\title{
Melodic Structure in Bill Evans's 1959 "Autumn Leaves"
}

\author{
Steven Strunk
}

\section{EDITOR'S PREFACE}

In March of 2014, a scholar made an inquiry at the John Donald Robb Musical Trust regarding a paper Strunk had delivered at the University of New Mexico sixteen years earlier. Strunk had presented at the John Donald Robb Composers' Symposium in March of 1998, which featured noted jazz composer Maria Schneider that year. Professor Richard Hermann of the University of New Mexico had arranged for a panel of jazz theorists consisting of Steve Larson, Henry Martin, Keith Waters, and Steven Strunk to participate at the symposium. It was the first time the acclaimed "Gang of Four" had ever assembled. ${ }^{\text {" }}$

Following up on the inquiry, the Trust contacted Professor Christopher Shultis of the University of New Mexico, a longtime director of the symposium. Shultis contacted Hermann, who had a copy of Strunk's handout. Hermann soon contacted Waters to see about obtaining a copy of the paper. Waters then reached out to Strunk's widow, Elena, who furnished the paper, as well as an abstract. At this point, all of the necessary materials had surfaced, and we found ourselves with a valuable piece of unpublished scholarship. As Martin and Waters had already been planning a Festschrift for Strunk, the venue for sharing this paper with the broader academic community was obvious. A short time later, all the documents made their way to me and I began to prepare them for publication.

The paper consists of a transcription of Bill Evans's performance of "Autumn Leaves" (primarily the right hand) from the album Portrait in Jazz, and an analysis in the form of a running commentary. While certain adjustments and alterations were necessary to prepare this paper for publication, the final product reflects Strunk's ideas in every way. The decision to retain certain features that might seem unnecessary today, such as the explications of contour segments and sentential organization, was motivated first by a desire to change the text as little as possible, but also because these passages so clearly reflect Strunk's patient, thorough writing style and his genuine, avuncular nature.

\footnotetext{
${ }^{1}$ Professor Hermann is credited with giving the group its name. Strunk, Waters, Martin, and Larson would go on to perform and present together several more times between 1998 and 2011.
} 
Many of the changes to the paper were minor, such as those one would make to accommodate a journal's style specifications. However, other differences between the original document and the final published version deserve mention. Strunk's handout had ossia-like staves with pitch reductions interspersed between the systems of the transcription. Here, the reader will find all such reductions as separate examples within the article's text. The complete transcription-consisting of eight choruses, an introduction, and an extended ending-is included in an appendix. While the original handout did not include chord symbols, it seemed appropriate to incorporate them in the examples that involved pitch reductions. Another important difference involves footnotes. Those in italics are not in Strunk's hand; they were inserted whenever it seemed that a point needed clarification. The inclusion of these comments seemed preferable to altering the original text.

The abstract for Strunk's original presentation reads "This paper aims to show how the performance makes a compelling improvisation through various methods of structuring time. This structuring takes place at the levels of motives, phrases, choruses, and the whole performance." His aim was certainly true. This paper showcases Strunk's inquisitive nature-his ability, as Waters once described, to "excavate significant data" from music of high quality. The reader will also notice how the analysis reveals a strong formalist bent at times. Henry Martin notes that while Strunk did study composition with such modernists as Roger Sessions, Vincent Persichetti, and Luciano Berio, he preferred to keep that often formalized world separate from his jazz playing. ${ }^{2}$ Fortunately, we find those two worlds intertwined in his analytical work.

"Melodic Structure in Bill Evans's 1959 'Autumn Leaves"” has much to offer in the way of analytical application. At the same time, however, Strunk's focus here has little to do with conventional concerns of jazz theory such as chordscale relationships, harmonic substitutions, or long-range contrapuntal frameworks. In this way, the article is quite forward-looking, despite the fact that it was written over fifteen years ago. Even while it remained unpublished, aspects of this study concerning rhythmic displacement directly contributed to scholarship in our field. ${ }^{3}$ And, as the centerpiece of this special issue of the Journal of Jazz Studies, this article is sure to inspire further inquiry into the analysis of jazz.

-Keith Salley

\footnotetext{
${ }^{2}$ Henry Martin, “In Memoriam Steven Strunk,” Journal of Jazz Studies 11, no.1 (2016): iii-v.

${ }^{3}$ See two references by Steve Larson: "Rhythmic Displacement in the Music of Bill Evans" in Structure and Meaning in Tonal Music: Festschrift in Honor of Carl Schachter (Hillsdale, NY: Pendragon Press, 2006): 103, and Musical Forces: Motion, Metaphor, and Meaning in Music (Bloomington: Indiana University Press, 2012): 195.
} 
Bill Evans's recordings of the late 1950s established him as a unique new voice in jazz piano playing. His harmonic voicings, substitutions, and his improvised lines sounded new at the time and have gradually influenced nearly all other jazz pianists who heard him. His lines, although basically derived from bebop, featured unusual rhythms and innovative melodic organization. Charles Blancq has written of Evans's "extraordinary ability in creating melodic lines that contain a very high degree of structural integrity." 4 The present study of the melodic lines of Evans's 1959 performance of "Autumn Leaves," aims to reveal some of the constituent processes by which, in at least this one case, such structural integrity was obtained.

In my opinion, the analytical tools used to convey an interpretation of a subject need not be part of that subject's cultural background. However, to bring to bear on Evans's melodic lines some of the theoretical concepts that normally are applied to "classical" music seems especially appropriate, as Evans's musical background was broad: he studied music first at Southeastern Louisiana University, then, in the years just preceding the recording in question, at the Mannes College of Music in New York. ${ }^{5}$ Evans has acknowledged being influenced by classical music, although "no more than [by] jazz," taking whatever he "liked the sound of." Of influences, he also said "all musical experience enters into you." His broad musical experience provided him with a rich array of melodic models.

Jazz performers are thought to hold analyses of jazz in low esteem. Evans expressed a negative opinion of analysis in a 1960 interview: "It's got to be experienced, because it's feeling, not words. Words are the children of reason and, therefore, can't explain it. . . That's why it bugs me when people try to analyze jazz as an intellectual theorem. It's not. It's feeling." However, his comments about his own use of theoretical ideas in his playing in a 1964 interview add a different point of view:

The only way I can work is to have some kind of restraint involved-the challenge of a certain craft or form-and then find freedom in that. . . Everything that I play, I know about, in a theoretical way, according to my own organization of musical facts. And it's a very elementary, basic-type thing. I don't profess to be advanced in theory, but in this area, I do try to work very clearly, because that is the only way I can work. ${ }^{9}$

${ }^{4}$ Charles Blancq, "Bill Evans: The First Trio," Jazzforschung 21 (1989): 57.

${ }^{5}$ Blancq, 55.

${ }^{6}$ Gene Lees, "Inside the New Bill Evans Trio," Downbeat 29 (November 22, 1962): 24.

${ }^{7}$ Nat Hentoff, "Introducing Bill Evans," Jazz Review 2 (October 1959): 28.

${ }^{8}$ D. Nelsen, "Bill Evans" Downbeat 27 (December 8, 1960): 16.

${ }^{9}$ D. Morgenstern, "Classic Interview—Bill Evans: The Art of Playing," Downbeat 61 (December 1994): 46. [Originally published October 22, 1964.] 
The construction of melodic lines was a subject to which Evans had given considerable thought: "Just learning how to manipulate a line, the science of building a line, if you can call it a science, is enough to occupy somebody for twelve lifetimes. ${ }^{" 10} \mathrm{He}$ added to this idea while discussing melodic coherence:

It's a problem, and one that I have in a way solved for myself theoretically by studying melody and the construction of melody through all musics. I found that there is a limited amount of things that can happen to an idea, but in developing it, there are many, many ways that you can handle it. ${ }^{11}$

Bill Evans recorded "Autumn Leaves" with bassist Scott LaFaro and drummer Paul Motian on December 28, 1959 for the album Portrait in Jazz (Riverside RLP 12-315 [M]). There were two takes of "Autumn Leaves." The first, issued on the original monaural version of the album, has been referred to as "preferred" by numerous critics; ${ }^{12}$ the second was issued on the later stereo version of the album. This study deals only with the monaural take. Another of Evans's innovations, the development of interactive, collective improvisation among the members of the trio, is demonstrated to a high degree in "Autumn Leaves." ${ }^{13}$ However, this study will concentrate on the structure of the melodic lines Evans played, without regard to their role in a "conversation" with the other players.

An improvised performance differs from a composition in that it occurs in real time, with no opportunity for the performer to go back and revise. The problems of maintaining interest and balance, of creating a sense of inevitability and forward motion are constant for the improviser. An analysis may choose to look at a transcription of a performance as if it were a composed score, moving backward and forward through it, collecting items for comparison that originally came into being for different local reasons. In contrast, the present study will move through the performance from beginning to end, just as Evans did, in an attempt to follow his ongoing solutions to the problems of "composing in the moment." ${ }^{" 14}$ The reader will find an annotated transcription of Evans's perfor-

\footnotetext{
${ }^{10}$ Ibid., 47.

${ }^{11}$ Ibid.

${ }^{12}$ For Example, Dick Katz and Martin Williams call it the "musically preferred ... version of the piece" in the booklet accompanying Jazz Piano: A Smithsonian Collection (1989, Smithsonian Collection of Recordings): 58. See also Blancq, "Bill Evans: The First Trio," 58.

${ }^{13}$ Evans intended this innovation: "I'm hoping the trio will grow in the direction of simultaneous improvisation. ... In a classical composition, you don't have a part remaining stagnant until it becomes a solo. There are transitional development passages - a voice begins to be heard more and more and finally breaks into prominence" (Hentoff, "Introducing Bill Evans," 26).

${ }^{14}$ The phrase is part of the title of Chapter 8 of Paul F. Berliner Thinking in Jazz: The Infinite Art of Improvisation (Chicago: University of Chicago Press, 1994).
} 
mance as an appended file. ${ }^{15}$ Please consult the transcription while reading the following discussion. Text references to measure numbers consist of a Roman numeral (the chorus number) followed by an Arabic numeral (the measure number within that chorus). Each chorus begins with measure one.

\section{INTRODUCTION}

The eight-measure introduction presents the chord progression of the repeated A section (mm. 1-16) of the tune in double time. The melody of each fourmeasure phrase moves down stepwise from $\hat{8}$ to $\hat{5}$, the head tone. This line is found across mm. 1-8 of the original melody as the first note in each occurrence of the sequenced motive (see Example 1A, lower staff). Returning to Evans' introduction, three sequential one-measure units lead to a cadence on the fourth measure. Measures 1-4 introduce syncopation and the motivic rhythm of two sixteenth notes leading into a downbeat. The varied repetition of the sequence in mm. 5-8 introduces quarter-note triplets grouped in pairs beginning with the second triplet quarter of $\mathrm{m}$. 5. This grouping presents a displaced hemiola that sounds three times in sequence. In addition to the $\mathrm{A}$ section progression and some particular rhythms, Evans's introduction has brought out sequence, hemiola, and rhythmic displacement as processes that will recur frequently in the choruses to follow.

A recurring feature of the melodic lines of this performance also begins in the introduction: the use of passages with symmetric contours, i.e., contours that have invariance under retrograde, inversion, or retrograde inversion. Perhaps the origin of this feature lies in the middleground of the melody of "Autumn Leaves" (Example 1) which includes $<\mathrm{E} b, \mathrm{D}, \mathrm{C}, \mathrm{B} b>$ in the A section, followed by $<\mathrm{A}$, $\mathrm{B} b, \mathrm{C}, \mathrm{D}>$ in the $\mathrm{B}$ section. The second segment is the transposed inversion of the first, whether represented as a pitch segment, a pitch-class segment, or a contour. ${ }^{16}$ If the two segments are concatenated, then the transposed inversion of

\footnotetext{
${ }^{15}$ Except for some minor rhythmic differences, my transcription of the performance agrees with that of Bob Hinz's in The Artistry of Bill Evans Volume 2 (New York: Warner Bros. Publications Inc. 1995). Hinz, however, does include the left hand throughout.

${ }^{16}$ The inversional relationship between these segments was pointed out in Keith Waters, "Outside Forces: 'Autumn Leaves' in the 1960s," Current Musicology 71-73 (Spring 2001Spring 2002): 284. Contours are notated here as they are in Robert Morris, Composition with Pitch Classes: A Theory of Compositional Design (Yale University Press, 1987), 27-36. Practically speaking, a set of pitches are assigned integers so that the lowest pitch is zero, the next lowest is one, etc. Then, the integers are placed inside angle brackets in the order that their corresponding pitches occur. Contours may be retrograded, inverted, or both at the same time. In the case of contours related by inversion, the sum of equivalent order positions is the highest
} 
that preserves the two discrete four-note segments in reverse order, again regardless of representation (Example 2$).{ }^{17}$

Example 1. Joseph Kosma, "Autumn Leaves," measures 1-24.

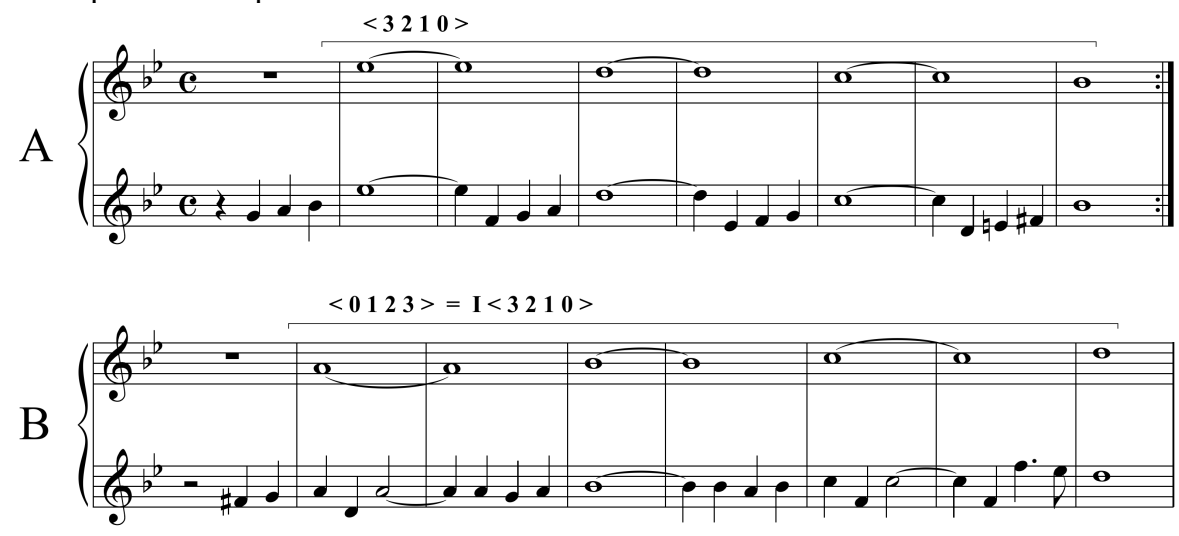

Example 2. Concatenation of middleground segments from A and B sections.

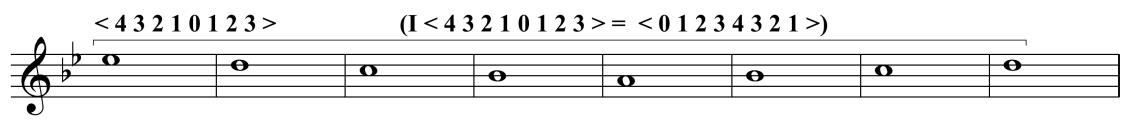

Symmetry is introduced in the introduction in a small way in mm. 2-3, where two inversionally related retrograde-symmetrical motives are concatenated to make a retrograde-inversionally symmetrical figure. (The first measure is slightly different, and is not so strictly retrograde-symmetrical.) In mm. 2-3, motives $<\mathrm{F}$, $\mathrm{G}, \mathrm{F}\rangle$ and $\langle\mathrm{E} b, \mathrm{D}, \mathrm{E} b\rangle$ have inversionally related contours $\langle 010>$ and $<101>$. Their concatenation produces contour <2 3210 1 >, which is invariant under retrograde inversion. This invariance holds also for pitch-class and pitch representations of $\mathrm{m}$. 3. (The set in this measure is 4-10 [0235], which is inversionally

integer in the contour so that the higher contour pitches are sent to the lower, and vice-versa. Transposition does not apply to contours. The concepts of pitch segment and pitch-class segment are also explained in Morris, 1987. Angle brackets enclose segments, which are ordered sets.

${ }^{17}$ That is, as a pitch-class segment, an inversion of the ordered series $<320 \mathrm{~T} 9 \mathrm{~T} 02>$ at $T_{0} I$ produces ordered series $\langle 9 \mathrm{~T} 02320 \mathrm{~T}\rangle$. Ordered elements within the discrete halves of each series are identical, but the halves themselves occur in a different order. Because pitches are as registrally close together as possible - and semitones are equivalent to interval classes - the same applies if we consider the elements as pitches rather than pitch classes. 
symmetrical.)

In the ensuing choruses, all of which contain improvisation, Evans strives for balance, variety, a sense of forward motion through various processes in time, melodic and rhythmic organizations that contradict the formal divisions of the original tune, and a unified shape for the whole performance. The following discussion will indicate some ways these ideals are obtained.

\section{CHORUS I}

As is usual, the first chorus paraphrases the original melody. Measures I-1 and I-3 contain single notes, a long one and a somewhat shorter one, as do mm. I-5 and $\mathrm{I}-7$, presenting the line $\langle\mathrm{E} b, \mathrm{D}, \mathrm{C}, \mathrm{B} b\rangle$ mentioned above. As this line is very close to the original, Evans takes a variety of liberties with the pickup groups that precede each of these notes. In the original song, these are each three ascending stepwise quarters beginning a sixth below each of the long notes to which they progress. Evans modifies each one in a different way, so that a sense of forward motion is obtained through the process of extending the pickup groups. At m. 8 of the Introduction, he adds a six-note prefix and a single eighth-note embellishment to the first pickup group. These additions enable the extraction of two retrograde-symmetrical subsets having contours $<\begin{array}{lllll}2 & 0 & 1 & 0 & 2\end{array}>$ and $<21012>$ (Example 3). The thirty second-note prefix actually sounds like a way of "crushing" the first of the three original pickups, so that this group sounds less modified than the following ones, basically consisting of four notes. The second group (m. I-2), also of four notes, recalls the syncopation and sixteenths of the introduction and begins the process of filling the interval of a sixth stepwise, but this time with a gap. The third group (m. I-4), of seven notes, fills the sixth completely with ascending stepwise motion, uniquely beginning with a repeated note. The fourth pickup group (m. I-6), of nine notes, adds a threenote "crush" prefix to yet another sixth-filling pattern, this one containing the retrograde-symmetrical subset $<\mathrm{G}, \mathrm{F} \#, \mathrm{D}, \mathrm{F} \#, \mathrm{G}>$, contour $<21012>$ (Example 4). Like this subset, most of the retrograde-symmetrical contours in this performance consist basically of ascents followed by descents or the reverse. Hence, they have the general forms $\langle 0 \ldots n . . .0\rangle$ and $\langle$ n...0...n $\rangle$, where $n$ is the highest element in the contour. For simplicity, I will call the former type an "up $(n+1) R S$ " contour and the latter type a "down $(n+1) R S$ " contour, where "RS" means retrograde-symmetrical. Thus, $<21012>$ is a down3RS contour. 
Example 3. Retrograde-symmetrical contours, Introduction, m.8.
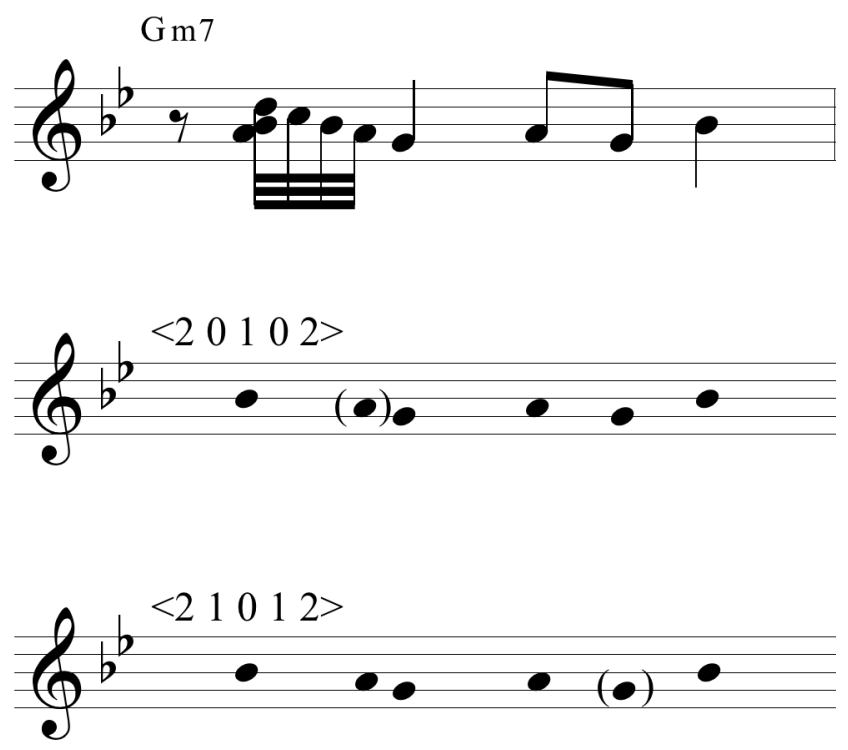

Example 4. Down3RS contour, I-6

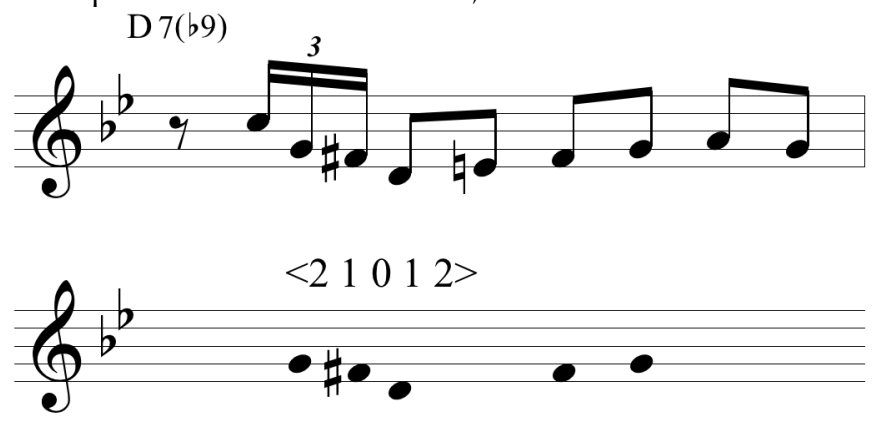

The next phrase begins to continue this process, starting the pickup group on the downbeat for the first time (m. I-8), but evidently the need for variety has led to an interesting effect: with the time and the progression continuing, the holding back of melodic motion in mm. I-9-13 has the effect of building tension. The pickup to m. I-11 only consists of the last two sixteenth notes before the downbeat; that to m. I-13, an ascending four-note arpeggiation of thirds. At the cadential pickup of the A section (m. I-14), it is as if the door has been opened and, releasing the tension, a flurry of eighth notes enters, consisting of an 
ascending dominant arpeggio followed by an ornamented descending tonic arpeggio across $\mathrm{m} . \mathrm{I}-15 .{ }^{18}$

This (mm. I-14-15) is one of a group of passages that exhibit segmental contour invariance under retrograde inversion. Such passages in this performance are generally constructed as a series of thirds in one direction followed (often at a change of chord) by a stepwise connection to a series of thirds in the other direction, filling the gaps in the first series, e.g., contour <0 $2431>$. Although this invariance is possible with ascents and descents of any degree of difference of size, Evans chooses forms in which they are either equal or differ by one note. I shall call this type an "interlocked" contour.

Example 5. Interlocked Contour, I-14-15.

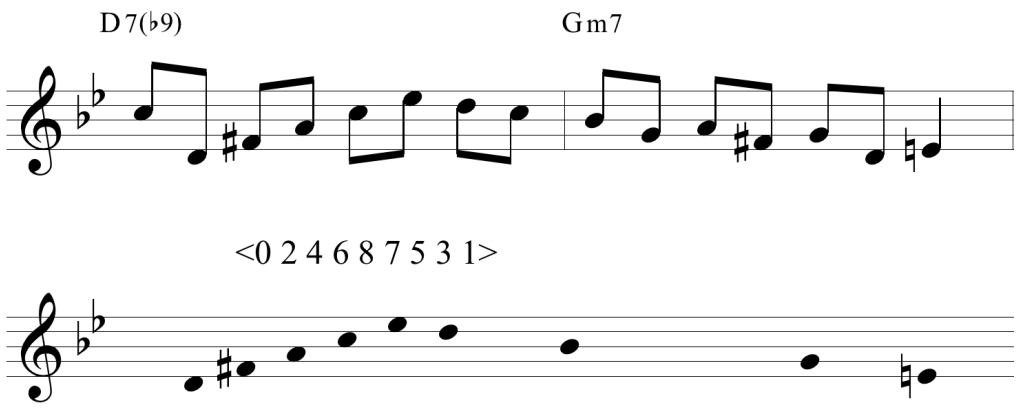

At $\mathrm{I}-14$ a reduction to chord arpeggiations produces interlocked contour $<02$ 468753 1>, which preserves segments <0 $2468>$ and $<7531>$ in reverse order upon retrograde inversion (Example 5). The amount of energy being released carries this passage beyond the downbeat, where it would normally end, so that it ends on an odd beat (the fourth) and an odd note (E⿱㇒日). ${ }^{19}$ The fourth beat (and sometimes the second) is a frequent endpoint for Evans's phrases, supporting the ideals of rhythmic displacement and incongruity with the original formal structure. After this release of energy, a measure's rest is taken.

The $\mathrm{B}$ section begins again to hold back melodic motion, but with the added interest of two-handed chords and a reminder of the displaced hemiola of the introduction at $\mathrm{m}$. I-17. The release of tension comes at $\mathrm{m}$. I-22, the high point

${ }^{18}$ In calling $\mathrm{m} . \mathrm{I}-14$ as the "cadential pickup of the $A$ section," Strunk refers to the cadence that provides structural closure for that section. The operative D7(b9) harmony at I-14 (not shown in the transcription), resolves to the global tonic Gm at the downbeat of I-15.

${ }^{19}$ The $\mathrm{E}$ finds resolution to $\mathrm{E} b$ in an inner voice line: $\mathrm{E}$ (m. I-15), F\# (m. I-17), F (mm. I-1718), E (m. I-19), Eb (mm. I-20-21). 
of the melody, and again the passage spills over past the cadential downbeat, ending this time squarely on the third beat. Across mm. I-22-23, the original melody $\langle\mathrm{F} 5 \mathrm{E} b 5$, D5 $>$ is given a suffix $\langle\mathrm{E} b 5, \mathrm{~F} 5\rangle$, producing a down3RS contour, which is followed immediately by a fill (m. I-24) of an up4RS contour, which contains the inversion of the previous down3RS contour as a subset (Example 6). Evans develops the melody-fill pattern of m. I-24 into a sequence, in which the fill provides the sense of forward motion by changing from a sevennote group (I-24) to a six-note group (I-26), then to a five-note group (I-28), with the latter two mimicking the contour of m. I-24. Although the middleground upper voice of the original tune ends with a stepwise descent to the tonic, in m. I-30 Evans delays the downward motion so that the line ends on A4, the ninth of the tonic chord that enters at the downbeat of $\mathrm{m} .31$.

Example 6. Retrograde-symmetrical contours, mm. I-22-28.
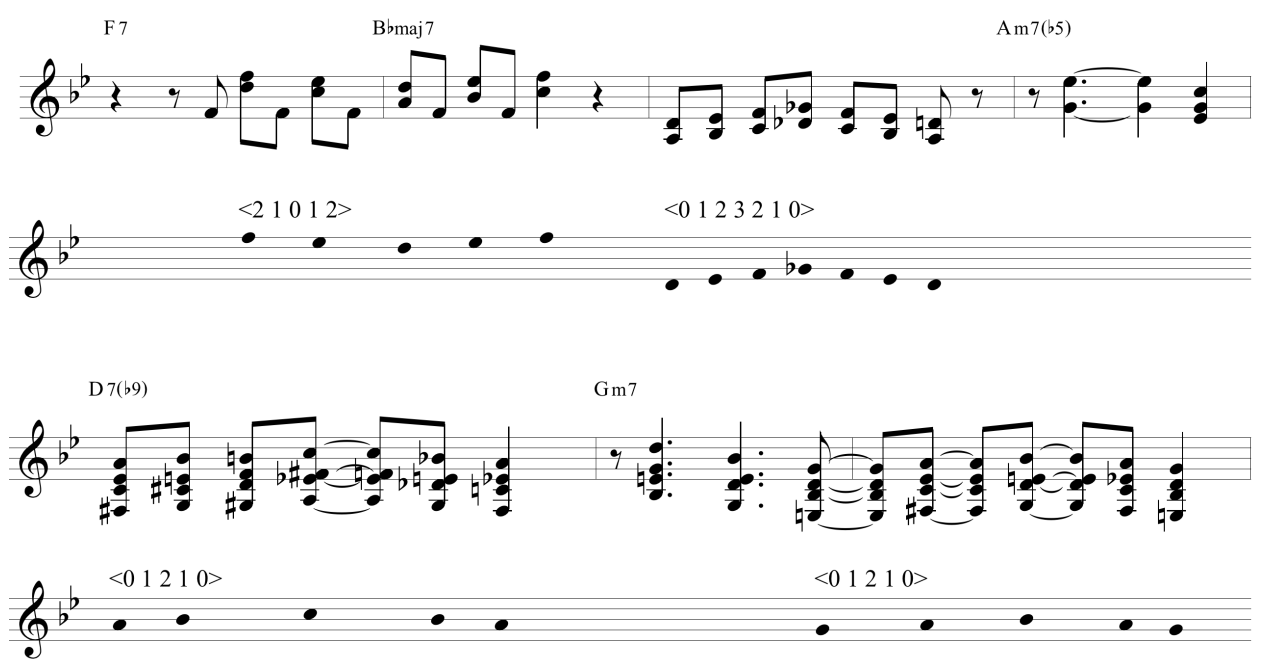

\section{CHORUS II}

The first improvised chorus is basically a bass solo, a choice unusual at the time and seen as an innovation. Evans participates actively, however, and continues to develop his own ideas in addition to responding to those of Scott LaFaro. While the bass is soloing, Evans plays lines in octaves in both hands, in contrast to the usual melody (right hand)/ accompaniment (left hand) assignment of function he uses at other times. ${ }^{20}$ In this chorus, after a rest of eight

${ }^{20}$ Octave doublings not shown in transcription. 
measures, Evans plays passages that generally increase in length and are separated by rests which increase and then decrease in length. The series of passage lengths in beats - with lengths of separations given in parentheses-is: 5, (3), 5, (7), 5, (7), 7, (9), 12, (6), 11, (3), 16. This process gives a strong sense of direction to the chorus.

The arpeggiations of $\mathrm{mm}$. I-12 and I-14 are recalled at II-9, 11, and 14 . Although, as indicated above, these groups have equal durations, Evans obtains a sense of growth by increasing the number of notes in each group. Example 7 shows the six-note group at II-9 (G4 is missing in the ascent, so this can only be classified as an up3RS contour). The group at II-11 has seven notes (an up4RS contour) followed by two "bebop" eighths anticipating the second beat. And, the group at II-14 has eight notes (but still an up4RS contour) followed by a denser pair of eighths, the first of which is harmonized.

Example 7. Up3RS contour, m. II-9.

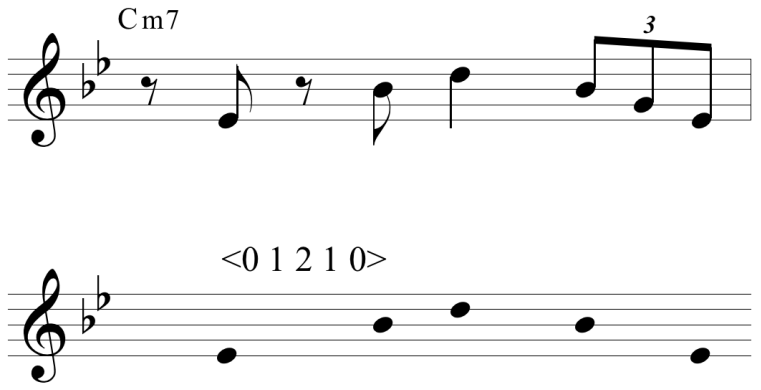

Because the thirteen-note passage at II-17 goes up and comes down, it appears to be a continuation of the earlier passages (although it consists primarily of steps). It introduces new ideas, however: the octatonic scale in II-17-18 has an ascent that is longer than the following descent. Here and in later choruses, some passages have ascents and descents that are unequal in length. In such cases, a core symmetrical contour has either its beginning or ending extended, producing a shape like a checkmark, or one of its transformations (inversion, retrograde, or retrograde inversion). ${ }^{21}$ At II-17, the shape is a retrograde-inverted checkmark. The reduction of the passage to an upward arpeggiation of the third, fifth, seventh, and minor ninth of an Am $7^{\left(b_{5}\right)}$ chord (II-17) followed by a downward arpeggiation of the fifth, third, and root of the $\mathrm{D} 7^{\left(b_{9}\right)}$ (II-18) results in the

${ }^{21}$ It would be possible to reduce "checkmark" passages to simple three-element contours (here, the contour would be $<1 \quad 02>$ ), but that would not convey the proportions of its directional segments. 
interlocked contour $<0246531$ 1 , which preserves segments $<0246>$ and $<5$ $31>$ in reverse order upon retrograde inversion (Example 8).

Example 8. Interlocked contour, mm. II-17-18.

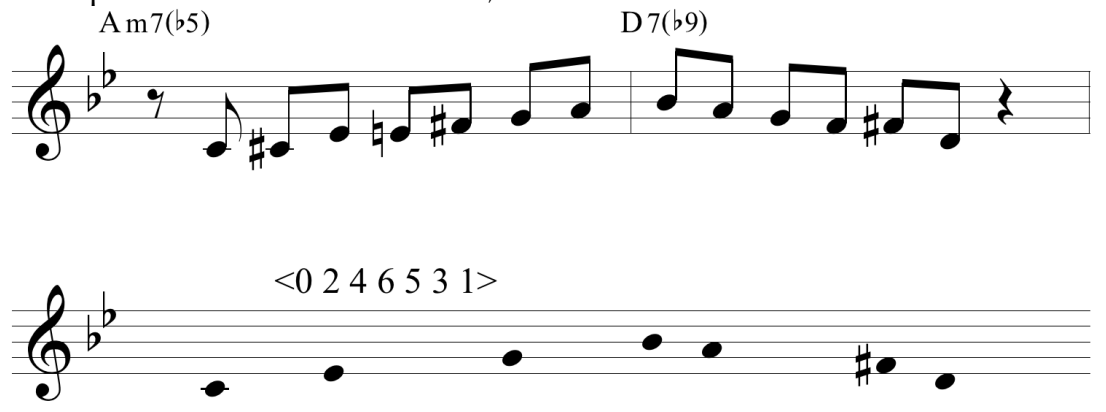

A reduction of the passage at II-21 reveals an inverted checkmark, the beginning contour of which is an up3RS type (Example 9, bottom staff). The octatonic scale is still present here, both in literal form descending between B5 and C5 (m. II-22), and as the source for the transposition level of the sequence in $\mathrm{m}$. II-21. As the octatonic scale is constructed by successive transpositions of ic2 at $T_{3}$, so the sequence is constructed by successive transpositions of the first four notes: $\langle\mathrm{F} 5, \mathrm{E} b 5 \mathrm{~B} b 4, \mathrm{G} 4\rangle$ at $\mathrm{T}_{3}$. The third entrance of the sequential motive is limited to its first two notes, $\langle\mathrm{B} 5$, A5 $\rangle$, which begin the descending octatonic scale. The registral isolation of this descending whole step through the sequence and its treatment in this passage (shown in Example 9) leads to consideration of another means of obtaining a sense of forward motion, that which Arnold Schoenberg called liquidation.

Example 9. Contour relationships, mm. II-21-23.
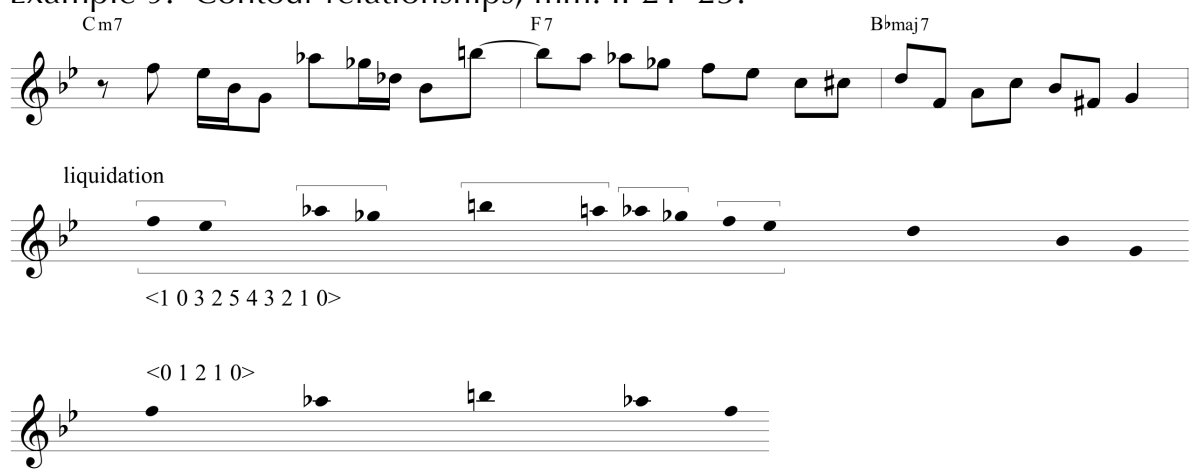
In Models for Beginners in Composition (1942), Schoenberg speaks o liquidation as "a method of getting rid of the obligations of the motif." ${ }^{22}$ Of this, he says, "Obligations of the motif derive from a tendency or inclination inherent in a motif by which it aims at developing variation." 23 These statements may be clarified by his reference to the technique of liquidation in Fundamentals of Musical Composition.

The technique to be applied... is a kind of development, comparable in some respects to the condensing technique of 'liquidation.' Development implies not only growth, augmentation, extension and expansion, but also reduction, condensation and intensification. The purpose of liquidation is to counteract the tendency toward unlimited extension.

Liquidation consists in gradually eliminating characteristic features, until only uncharacteristic ones remain, which no longer demand a continuation. Often, only residues remain, which have little in common with the basic motive.

The liquidation is generally supported by a shortening of the phrase. ${ }^{24}$

In the ensuing discussion, the concepts of reduction, shortening, intensification, and condensation stand out as the main characteristics of liquidation. Although not emphasized by Schoenberg, the application of these processes also results in a sense of accelerating forward motion toward the end of the liquidation, after which the idea being liquidated is not heard again for some time.

In the passage at II-21, the repetition and compression of the downward whole-step might be seen as a liquidation. Its first three statements are separated by three quarters of a beat, followed by two contiguous statements after which none is heard except perhaps for a brief echo $\langle\mathrm{C} 5, \mathrm{~B} b 4\rangle$ in $\mathrm{m}$. II-23. Considering the liquidated elements as a segment $\langle\mathrm{F}, \mathrm{E} b, \mathrm{~A} b, \mathrm{G} b, \mathrm{~B}, \mathrm{~A}, \mathrm{~A} b, \mathrm{G} b, \mathrm{~F}, \mathrm{E} b>$, its contour is <1 $032543210>$, which holds contours $<103254>$ and $<54$ $3210>$ invariant in reverse order under retrograde inversion (Example 9). ${ }^{25}$

The sequenced motive at II-21 occupies three eighth notes and begins on the second half of the first beat, thereby setting up a displaced hemiola, a descendant of mm. 5-7 of the introduction. Given the usual stress on the offbeat eighth notes of bebop lines and the contour accents on C5 in m. II-22 and F4 in m. II23, another displaced hemiola might be heard to begin on $\mathrm{G} b$ in $\mathrm{m}$. II-22,

${ }^{22}$ Arnold Schoenberg, Models for Beginners in Composition (New York: G. Schirmer, 1942): 11.

${ }^{23}$ Ibid., 15.

${ }^{24}$ Arnold Schoenberg, Fundamentals of Musical Composition, ed. Gerald Strang and Leonard Stein (New York: St. Martin's Press, 1967): 58.

${ }^{25}$ This would be true considering the notes as either pitches or pitch classes. 
extending to the end of the passage. ${ }^{26}$ Like the passage at $\mathrm{mm}$. I-14-15, this passage extends beyond the formal section cadence (i.e., the downbeat of II-23) and ends on the fourth beat. Its last three notes are a transposition $\left(\mathrm{T}_{3}\right)$ of those that close the earlier passage.

The next passage at II- 25 also begins with sequence and hemiola, but the hemiola is not displaced. The interval of 3 semitones is present here not as a transposition level, but as the interval separating the members of the trichord 310 [036], the subject of sequential treatment. A reduction to an ascending arpeggiation of the dominant 69 chord (II-26) followed by a descending arpeggiation of the tonic chord (II-27) reveals interlocked contour $<135798$ (6) 42 $0>$ in which element 6 is missing from the descent (Example 10). This condition results in slightly incomplete invariance of the reversed segments upon retrograde inversion: only $\langle 8420\rangle$ and $\langle 1579\rangle$ are preserved. The repeated 310 [036] trichords at the beginning of the passage can be understood as a repetition and compression of the segment $\langle\mathrm{F} 5, \mathrm{~A} b 5, \mathrm{~B} 5\rangle$, which consists of the first notes of each occurrence of the sequenced motive in the previous passage at $\mathrm{m}$. II-21. Incorporating the F5 at II-21, the starting pitches of these trichords (G4, A4, B4, and C5) also ascend by either interval class 2 or 1 , further connecting the five instances. Repetition and compression also occurs with a rhythmic motive (labeled M1), which first occurs at m. II-26, occurs again after four eighth notes, and occurs again after only two eighth notes. Like the others, this passage extends beyond the cadence of the phrase (II-27) to end on an anticipation of the second (weak) beat of m. II-28.

Example 10. Interlocked contour, mm. II-26-27.

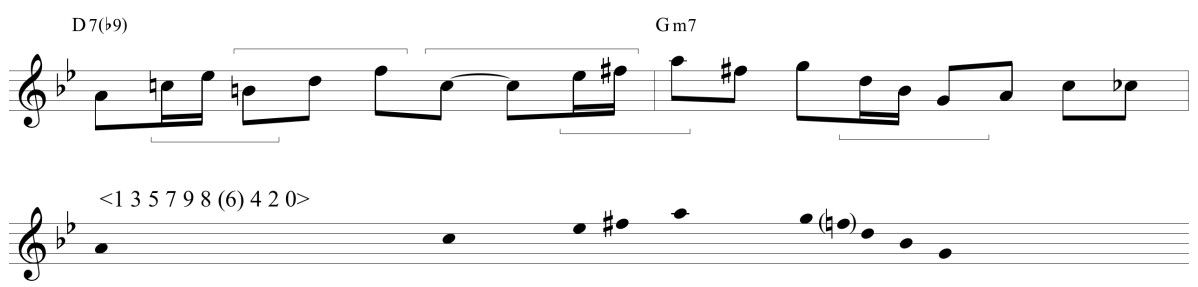

The final passage, at II-29, begins with rhythmically straightforward sequences and descends gradually, producing no notable symmetrical contours. The construction of the passage brings to mind, however, Schoenberg's concept of the sentence. In Models for Beginners he writes of a sentence, "The opening phrase is repeated at once (with or without variation). This repetition makes further

${ }^{26}$ See dashed brackets in the transcription. 
exact repetitions unnecessary, and permits a continuation with either reduced forms of the basic phrase or more remote motif-forms." ${ }^{27}$ The passage at II-29 can be seen as a miniature sentence: the opening phrase is in $\mathrm{m}$. II-29, its sequential repetition is in $\mathrm{m}$. II-30, and $\mathrm{mm}$. II-31 and 32 are the continuation. The first five notes of the continuation are a varied repetition of the sequence motive, and its last four notes can be seen as a form of the sequence motive reduced both in range and rhythmic duration ("residue").

\section{CHORUS III}

In the third chorus, the bass solo continues. Although the durations of Evans's passages vary irregularly, the silences between them undergo three successive processes of growth. In terms of beats of silence, these are (1) 4, 5, and 12 across mm. III-1-11; (2) 2, 3, and 5 across mm. III-12-17; and (3) 4, 5, and 6 across $\mathrm{mm}$ III-21-29. The first sixteen measures continue the motivic and developmental processes started earlier; the last sixteen present a small AA'BA" form.

Measure III-1 presents contour $<2 \quad 01>$, the inversion of the contour of the last three notes of the preceding measure, $<021>$, thereby connecting the two choruses. The next passage (at III-3) varies the activity between D4 and F4 that began in III-1 and imitates chromatic motion begun a few beats earlier by the bass (not shown). The chromatic triplets seem to "wind up" for their extended ascent at the end, thereby escaping the repeated closed up4RS contours with which they began. The ascent produces a checkmark shape in III-4, and the passage ends with a triplet on a weak beat. In the next passage at III-6, following a linear ascent from $\mathrm{G} 4$ to $\mathrm{E} b 5$, an elaborated descent recalls the aforementioned arpeggio motive of chorus II and, when reduced, produces an up5RS contour (Example 11).

Example 11. Up5RS contour, mm. III-6-8.
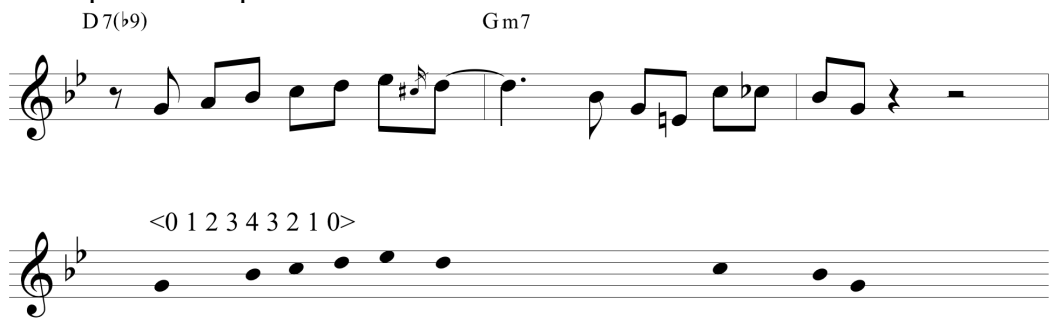

${ }^{27}$ Schoenberg, Models for Beginners, 16. 
Three sequential motivic statements occur across mm. III-11-16. Here, the two hands continue to proceed in octaves, however, the upper line is now harmonized below, mainly in parallel thirds. Each statement is based on the idea of an upper neighbor stepping downward through an arpeggiation in thirds with differing degrees of elaboration (Example 12). The three statements involve repetition and compression, as can be seen by listing the durations (in eighth notes) of the notes of each as they approach the goal of their downward motions and the total duration of each: $(1)<1,2,2,2,2\rangle$, total $9 ;(2)<1,2,1,2,1\rangle$, total 7 ; (3) $<1,1,1,1,1,1,1,1,1>$, total 9. Although the last group, like the first, totals 9 eighths, the gradual move to shorter values supports the feeling of compression and concomitant liquidation.

Example 12. Elaborated arpeggios, mm. III-11-16.

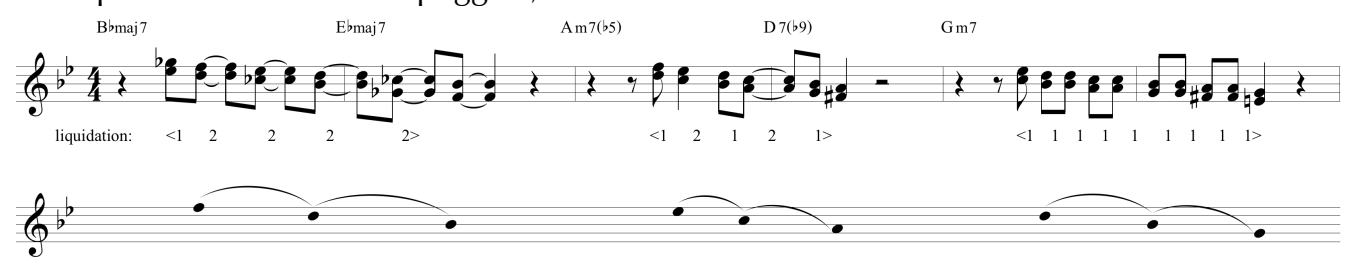

Two groups of three measures each, mm. III-18-20 and III-22-24, resemble each other. Evans plays ascending chord arpeggiations of varying sizes: 3, 4, 4, and 5 notes in $\mathrm{mm}$. III-18-20, ending on the fourth beat; and 4, 3, 5, 5, and 3 notes in $\mathrm{mm}$. III-22-24, ending on the anticipation of the fourth beat. ${ }^{28}$ These groups, occupying mm. III-17-24 (including rests), serve as the first section of a small AA'BA" form. The B section consists of $\mathrm{mm}$. III-25-28, in which six-note vertical chords are played. The return to the arpeggio idea (A) at $\mathrm{m}$. III-29 begins with a three-note vertical chord and reverses the direction of the arpeggiation, balancing the earlier ascents. All the verticals across mm. III-26-27 segment into trichordal octatonic subsets: 3-7 [025], 3-8 [026], and 3-10 [036], while the first two verticals comprise the tetrachordal subset 4-27 [0258]. The chorus ends with a small checkmark shape: at III-31 a down3RS contour is extended upward at its end by one note.

${ }^{28}$ Strunk derives the final arpeggio in the first group from those notes that fall squarely on beats (thus, F\#4, G4, Bb4, D5 and A5). 


\section{CHORUS IV}

This chorus, a piano solo, features numerous liquidations. It begins with a retrograde-inversionally symmetrical figure of contour $<1210$ 1>. An up4RS contour beginning at $\mathrm{m}$. IV-7, beat 4 is extended by three notes at the end, forming an inverted checkmark (Example 13). ${ }^{29}$ This passage also presents repetition and compression: consider the decreasing durations between instances of the note G5. It enters on the downbeat of IV-8; the time to its next occurrence is 6 eighths; to the next, 5 eighths, then 2, 2, 2, and 2 eighths. We no longer hear the note for a while after that. At the same time, three occurrences of the rhythmic motive M2 (beginning in IV-9) are separated first by 2, then 0 eighths. In this way, motive M2 is also liquidated.

Example 13. Up4RS contour and inverted checkmark, m. IV-8-9.

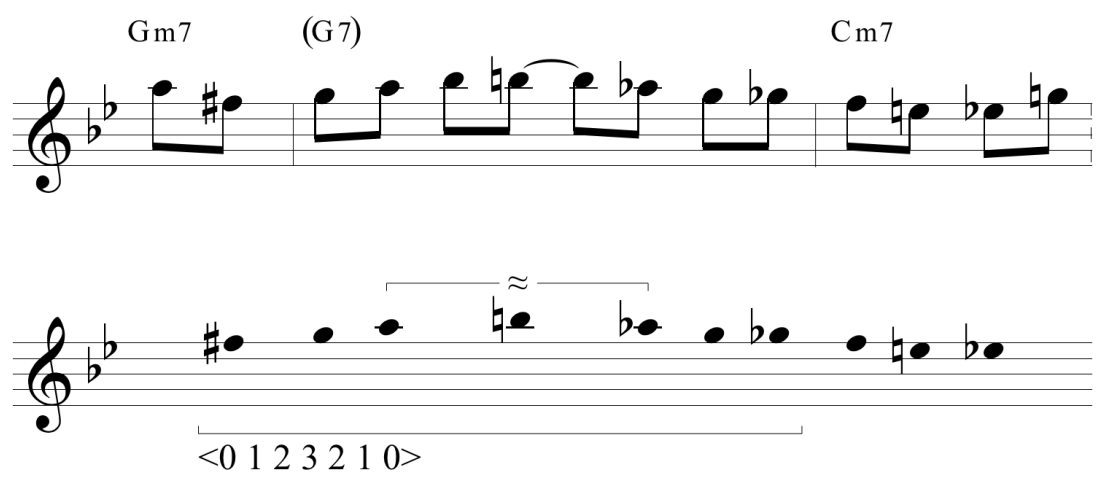

A slight reduction of the beginning of the next passage at IV-11 reveals a down5RS contour which is extended upward at the end to the downbeat of $\mathrm{m}$. IV-13 to form a checkmark shape (Example 14). Although the melodic motion continues past the sectional cadential downbeat at IV-15 to end on an anticipation of the second beat of $\mathrm{m}$. IV-16, the $\mathrm{D}$ on that sectional downbeat is the goal of a process of compression that begins on $\mathrm{Bb5}$ in $\mathrm{m}$. IV-13. The stepwise descending upper voice of the contrapuntal melody is elaborated by descending arpeggiations derived from m. I-9 (Example 15). These elaborations cause the effective durations (in eighth notes) of the downward arpeggiations from those notes of the upper line to decrease as follows: Bb (4), A (4), G (3), F (2), Eb (2), $\mathrm{D}$ (goal), creating a liquidation of descending arpeggiations.

${ }^{29}$ Strunk's handout featured the '= ' (equals) sign here. However, the double tilde (meaning "approximately equal to") more accurately accounts for the general equivalency of the functions of $A$ and $A b$ in this passage. 
Example 14. Down5RS contour, mm. IV-11-12.

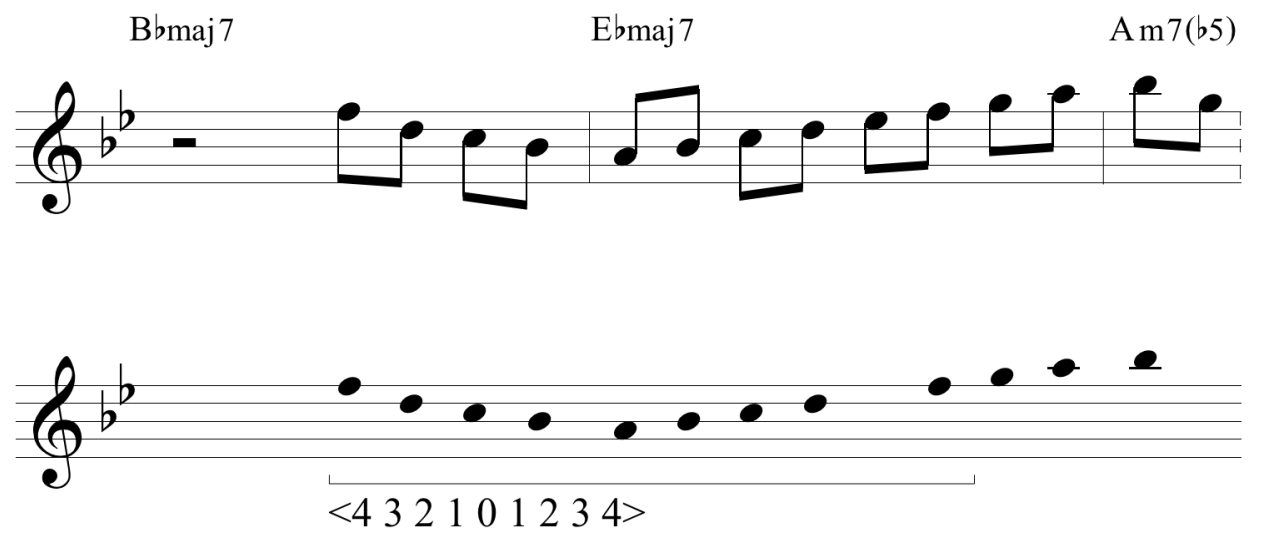

Example 15. Upper-voice descent, mm. IV-13-15.

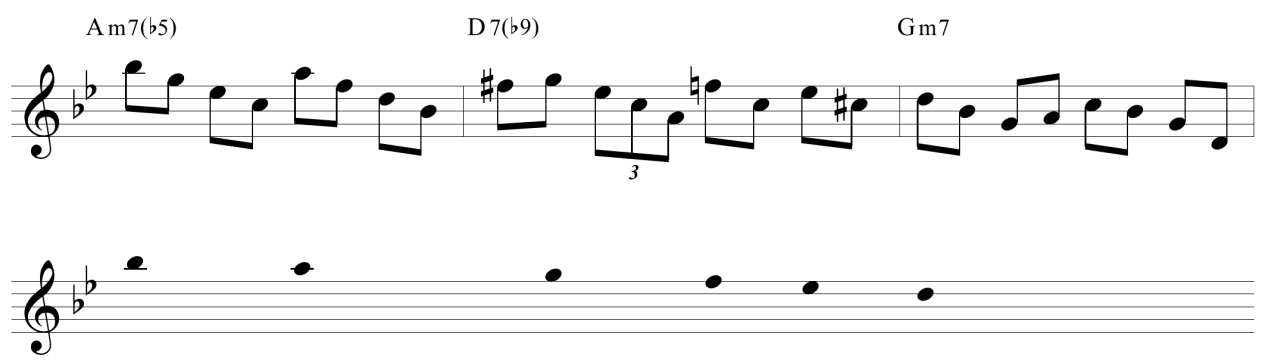

The first five notes of the passage at $\mathrm{m}$. IV -17 present a down3RS contour, and the two-octave ascent of that measure is matched by a two-octave descent in the next. At the peak is a small interlocked contour, <0 $2431>$, which preserves segments $<024>$ and $<31>$ in reverse order on retrograde inversion.

Across IV-25-27, scalar passages connect the following extremes: G3/A4, A4/D4, D4/D5, D5/G4, and G4/A5>. This set, in pitch integer notation <-5, 9, $2,14,7,21>$, is invariant under $\mathrm{RT}_{16} \mathrm{I}^{30}$ When notated as contour $<031425>$, it is also invariant under retrograde inversion. The ascending portions of the passage each occupy approximately three beats, while the descending portions occupy one. These proportions produce a combination of checkmark and retrograde-inverted checkmark shapes. These include an up5RS contour across mm. IV-25-26 and a down5RS contour at m. IV-26-27 (Example 16).

${ }^{30}$ Pitch integer notation accounts for distances of each member of a set of pitches from middle $C$ (here, the set is ordered). See Rahn 1980, 19-39. To perform the operation $R T_{16} I$, invert all pitches around middle $C$, transpose them sixteen semitones, and then put the result in reverse order. 
Although the general plan of the passage is regular, its details are unique, being involved in developmental processes. Hemiola results from grouping the first three beats (triplet eighth notes) and the next three (sixteenths ending on the second sixteenth of the last beat). ${ }^{31}$ The next four beats may be grouped together, as they are mostly sixteenths, again ending on the second sixteenth of the last beat. Two beats remain, so the passage ends on the fourth beat of $\mathrm{m}$. IV-27.

Example 16. Contour relationships, mm. IV-25-30.

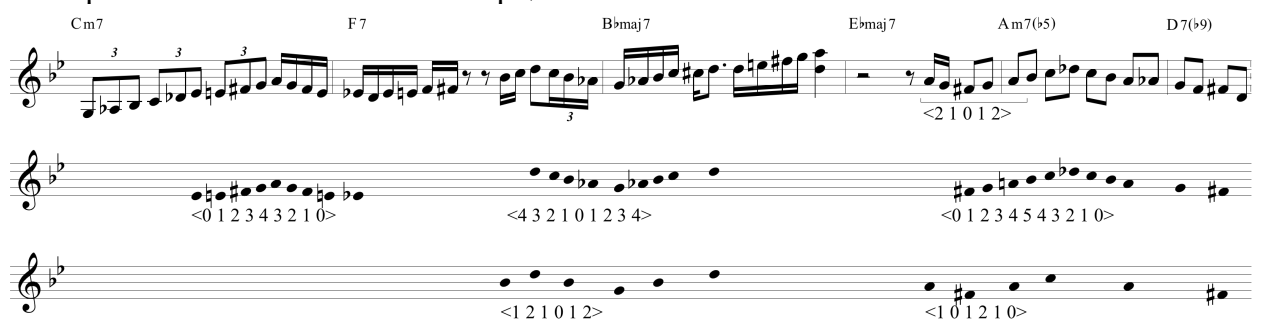

Another way of expressing the implied meter of the passage beginning at IV25 , which would reflect its feeling of compression and forward motion, would be as one measure of $6 / 4$ followed by one measure of $4 / 4$ and one measure of $2 / 4$. The repetition and shortening of units throughout the passage supports this grouping. The unit first occupies the 6/4 "measure" and consists of a long ascent to A4, a quick descent to $\mathrm{D} 4$, and a quick ascent to $\mathrm{F} \sharp 4$ one beat later. The next statement of the unit occupies the 4/4 "measure." Here the initial ascent to D5 has been shortened to three notes. The ensuing down5RS contour makes a quick descent to G4 followed by a quick ascent back to D5. The final statement of the unit occupies the 2/4 "measure" and has been stripped of all but its final ascent from $\mathrm{D} 5$ to $\mathrm{A} 5$.

The passage at IV-28 begins with a turn, i.e., a down3RS contour, which overlaps with an up6RS contour beginning in IV-29 (Example 16). The descent of that contour is elaborated, and the sequential continuation of the elaboration in IV-30 produces the inverted checkmark shape (see score). This passage connects with $\mathrm{mm}$. IV-26-27 in that they can both be reduced to arpeggiations in thirds whose contours are related by inversion (Example 16, bottom staff).

${ }^{31}$ Here, Strunk refers to a hemiola of rhythmic textures, where a durational span of six beats divides into one half (comprised of triplet eighths) and another (comprised of sixteenths). In this way, two roughly equal units of different rhythmic texture combine to form a span that is temporally divisible by three. 
Example 17. Contour relationships, mm. IV-31-32.
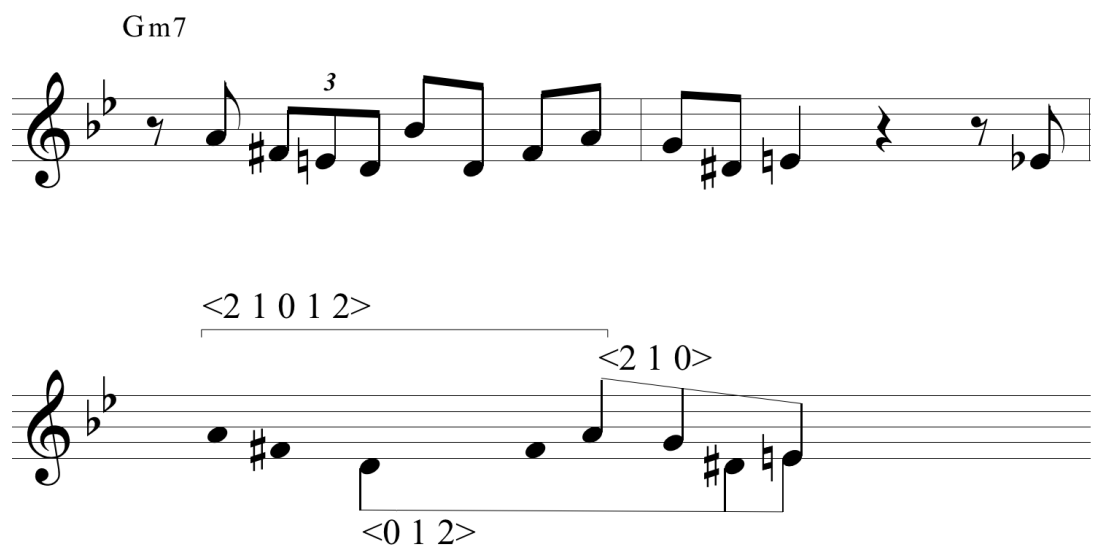

The next passage at IV-31-32 also reduces to an arpeggiation in thirds. In this case, the arpeggiation forms a down3RS contour (Example 17). The end of this passage contains - as polyphonic lines converging on $\mathrm{E}$ - an upper voice contour $<210>$ and a lower voice contour $<1 \quad 2>$ which are inversions or retrogrades of each other (see stemmed notes). The last two beats of this passage are identical to those of I-15, ending on the "odd" note and weak beat.

\section{CHORUS V}

The piano solo continues. This chorus is devoted to motivic development and the introduction of an expansive melodic model that will be used repeatedly in chorus VI.

The opening eighth note triplets, recalling $\mathrm{mm}$. III-3-4, attach chromatic lower neighbors to third arpeggiations producing the partially interlocking contour <0 2467653 1> (Example 18). Note the retrograde-symmetrical central contour subset $<676>$. Omitting its central element 7 reveals the interlocking contour <0 24653 1>, first seen at m. II-17. Measures V-3-8 feature a reversal of the liquidation process, where motivic residues originally compressed into mm. V-1-2 are presented at increasing time intervals: twice after one beat, then again after three beats. ${ }^{32}$

\footnotetext{
${ }^{32}$ Blancq, "Bill Evans: The First Trio," 58, notes that this is one of several passages that "reveal a rudimentary sense of motivic relationships."
} 
Example 18. Partially interlocking contour, mm. V-1-2.

$$
\mathrm{Cm} 7
$$

F 7

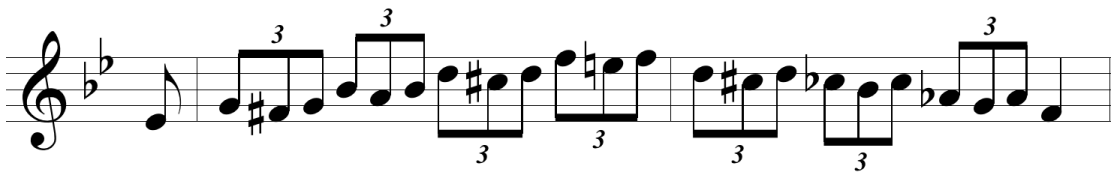

$<024676531>$

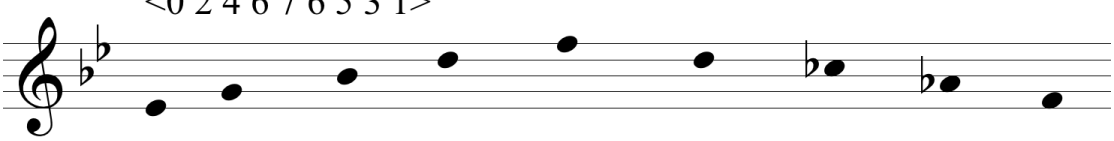

A passage begins at $V-9$ that continues unbroken to the downbeat of $V-19$. One way to articulate it is to observe that the note G4 occurs at four salient moments: at the beginning, at the end, as the first note of $\mathrm{m} . \mathrm{V}-13$, and as the last note of $\mathrm{m} . \mathrm{V}-14$. The latter two locations enclose a passage with symmetrical properties similar to those of $\mathrm{mm}$. V-1-2. To consider this smaller passage first, note that its contour is the combination of three overlapping contours, <0 1234 5>, <1 20 1>, and <5 $43210>$ (Example 19). The central contour is retrograde-inversionally symmetrical, and prolongs element 5 of the surrounding contours; omitting it reveals contour <0 123465432 0>, which preserves <0 $12346>$ and $<654320>$ in reverse order on inversion.

Example 19. Contour relationships, mm. V-13-14.

A m7(b5)

D 7(b9)
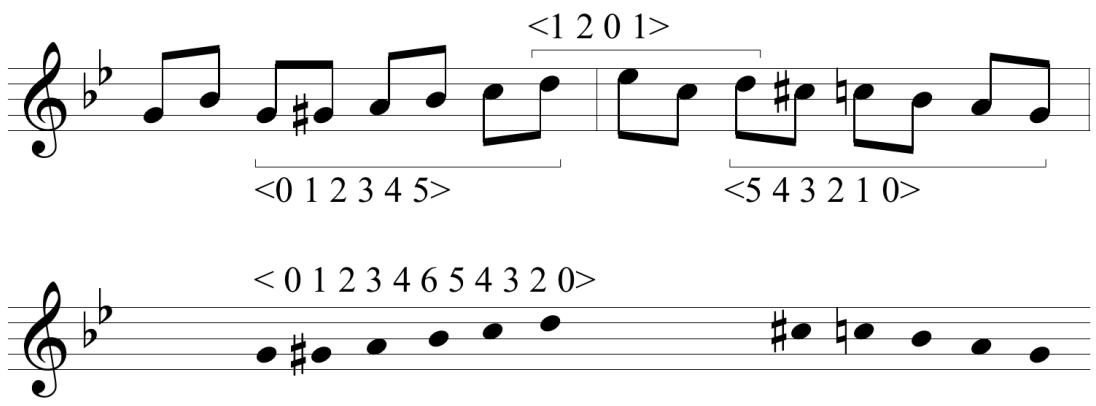

The passage from $m . V-9$ to the downbeat of $m . V-13$ dramatically opens the melodic range, beginning on $\mathrm{G} 4$, ascending to $\mathrm{Ab6}$, descending to $\mathrm{C} 4$, and returning to $\mathrm{G} 4$, thereby describing an inverted checkmark interlocked with a retrograde checkmark. Many of its pitches and rhythms will be developed in similar passages in chorus VI. 
The retrograde-symmetrical contour of the residual motive at m. V-3, <0 21 $20>$, is related to that of the repeated pattern in mm. $\mathrm{V}-15-18,<20102>$, by inversion. This pattern occurs twice in eighth notes in $\mathrm{V}-15$, then is imposed on triplet eighths in mm. V-16-18. The high note of each pattern in the triplets combined with the four beats of the measure produces the polyrhythm three against four in each of those measures. The intervallic content of the pattern narrows as it approaches the goal, the downbeat of $\mathrm{m}$. V-19: 3-6 [024] in $\mathrm{mm}$. $\mathrm{V}-15-16,3-2$ [013] in mm. V-17-18. The series of high notes from each form of the pattern, $<F \# 4, A 4, A b 4>$, close in melodically on the goal G4 at the downbeat of $\mathrm{V}-19$, and the four-note contour that results, <0 $321>$, preserves its discrete dyads in reverse order upon retrograde inversion.

A short passage in $\mathrm{mm}$. V-19-20, on reduction an up4RS contour, prolongs $\mathrm{G}$ (Example 20). That passage and one other interrupt the appearances of triplet passages between $\mathrm{m}$. V-16 and $\mathrm{m}$. V-31. The second interrupting passage, $\mathrm{mm}$. $\mathrm{V}-25-26$, resembles the expansive one beginning at $\mathrm{m}$. V-9. Both have an inverted checkmark shape, ${ }^{33}$ cover a fairly wide range, use quarter-note triplets around their highest point, and on their descents use a characteristic rhythmic fragment (m. V-10, beats three and four, m. V-26, beats one and two) which will be developed further in chorus VI. Immediately after this (mm. V-27-28) is a passage shaped as an inverted checkmark beginning with an up5RS contour, resembling many earlier passages (Example 21).

Example 20. Up4RS contour, mm. V-19-20.

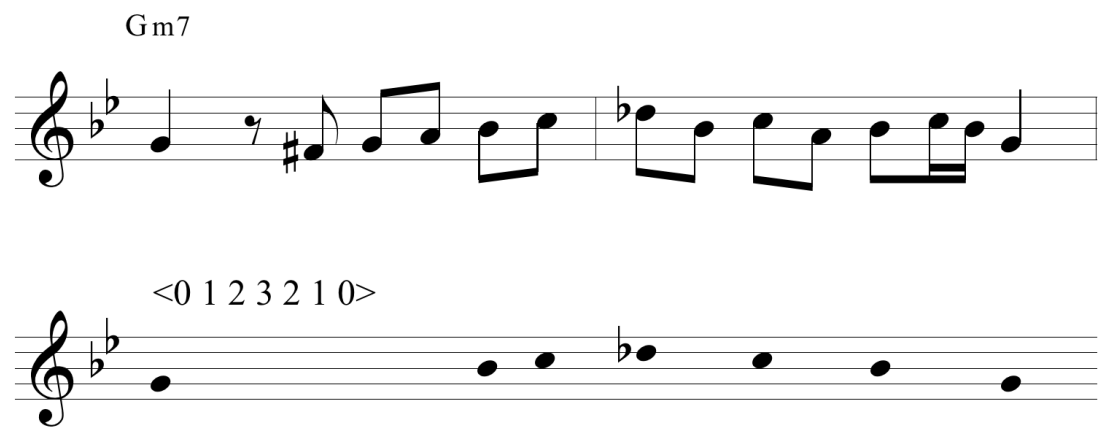

${ }^{33}$ While Strunk's observation is true, the contour across $\mathrm{mm} . \mathrm{V}-9-10$ is a retrograde-inverted checkmark. 
Example 21. Up5RS contour, mm. V-27-28.
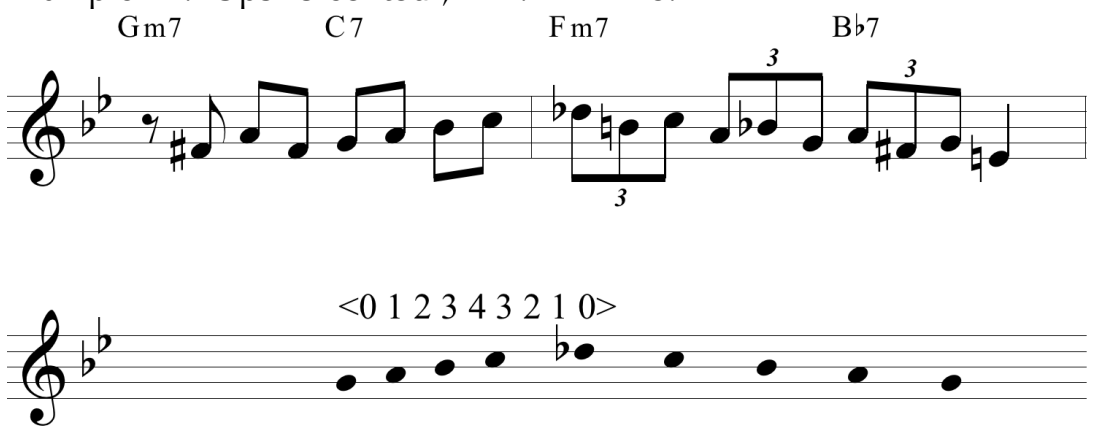

By using the triplet passages at irregular time intervals and by interrupting them, Evans is able to build a half-chorus from a simple motive without being predictable. Most of the triplet passages end on the last third of a beat, giving a sense of disconnection from the phrasing of the original tune. (The one passage that ends on the beat ends on a fourth beat E$\boxminus$, modeled after m. I-15.) Variety is also served by the abandonment of the $<20102>$ contour after $\mathrm{m}$. V-23, except for a brief return $\mathrm{m}$. V-29. The durations of the triplet passages and the rests between them are given in Table 1 . After the first long group, there is a slight but general decrease in the length of the groups which might possibly add to the sense of direction in this section. The "beats intervening" column shows that after the first interruption, passages consisting of three triplets are separated by first one and one-half beats, then two and one-half beats, etc. These varying lengths allow the triplet passages to fall irregularly against the meter. At the same time, however, the twelve intervening beats observe the division between $\mathrm{B}$ and $\mathrm{C}$ sections of the tune.

Table 1. Use of Triplet Groups in Chorus V

\begin{tabular}{|l|l|l|}
\hline starting measure & beats of triplets & beats intervening \\
\hline 16 & 12 & 8 \\
\hline 21 & 3.5 & 1.5 \\
\hline 22 & 3.5 & 2.5 \\
\hline 23 & 3.5 & 12 \\
\hline 28 & 3 & 1.5 \\
\hline 29 & 3.5 & 2.5 \\
\hline 31 & 2.5 & \\
\hline
\end{tabular}




\section{CHORUS VI}

This chorus features many of the rhythmic and melodic patterns most unique to Bill Evans, which were admired and absorbed by others, gradually becoming part of the general repertoire of most jazz pianists. As mentioned before, one general rhythmic characteristic is the stopping of lines on a weak beat (the second or fourth beat) or on an off-beat anticipation of one. All the passages in this chorus have this characteristic. Some passages also start on a weak part (usually the second half) of the first beat, as in mm. VI-4, 11, 15, 18, 19, 21, 25, 26, and 29. These rhythmic characteristics cause the line to seem to float disconnected from the ongoing 4/4 beat of the tune in a manner distinct from that of earlier performers. The general juxtaposition of long series of eighth notes with long series of quarter-note triplets is also distinctive of Evans' style.

One important rhythmic pattern is an anacrusis of two fast notes approaching an accented note followed by another note ending the group (labeled M3). The latter two notes have longer durations (at least before subsequent note onsets) than the two upbeat notes. A single case occurs at VI-4, beat four. Successive patterns occur across VI-11 and VI-12. Sequences of the pattern begin at VI-6, VI-12 and at VI-22. Relative durational values are reversed in the sequence of motives (labeled M3R) beginning at VI-9, beat two, so that the slower pair precedes the faster. ${ }^{34}$ In $\mathrm{m}$. VI-18, the two final eighth notes of the pattern are extended to five. In VI-27, two occurrences of the pattern (with the modification that the final note does not end the pattern) are overlapped in the pitch series $<\mathrm{C} 6, \mathrm{~B} b 5, \mathrm{G} 5, \mathrm{D} 5>$ and $<\mathrm{D} 5, \mathrm{D} b 5, \mathrm{C} 5, \mathrm{~A} 4>$.

The main innovative pitch characteristic of these passages is the use of the octatonic scale. The presence of numerous octatonic passages argues for a more conscious use of the scale than was the general practice of the time. Such passages using octatonic subsets of five or more pitch classes in chorus VI are listed in Table 2.

Measures 1-16 of this chorus present a series of passages each of which ascends and then descends. The range and duration of these gradually decreases, supporting the impression that the section begins with high energy and gradually subsides. The first passage, a three-measure phrase, ascends to the melodic peak of the section, $A b 6$ and descends one step short of tonic, to A4, resulting in a total range of 23 semitones. The next passage (mm. VI-4-8), a four-measure phrase shifted one measure ahead of the comparable phrase of the tune, ascends

${ }^{34}$ In truth, each of these motives finishes with a triplet quarter, which is actually longer in duration than the straight eighths at motive onsets. However, Strunk is phenomenologically accurate, as one still hears each of these motives conclude with two relatively swift attacks. 
only to $\mathrm{F} \# 6$ before descending to $\mathrm{B} b 4$, reducing the range to 20 semitones. The next four passages are each two measures in length, having ranges of 19 (Bb4F6), 17 (C6-G4), 12 ( $\mathrm{B} b 5-\mathrm{B} b 4)$, and 7 ( $F \sharp 4-\mathrm{D} b 5)$ semitones respectively.

Table 2. Use of Octatonic Subsets in Chorus VI.

\begin{tabular}{|l|l|l|l|}
\hline starting measure & first note & last note & ending measure \\
\hline 2 & A5 & C5 & 3 \\
\hline 5 & D6 & C6 & 6 \\
\hline 9 & D6 & C5 & 11 \\
\hline 15 & F $\# 4$ & G4 & 16 \\
\hline 17 & G4 & F $\$ 5$ & 17 \\
\hline 18 & Ab5 & D5 & 18 \\
\hline 19 & F 5 & G5 & 20 \\
\hline 22 & A5 & C5 & 23 \\
\hline
\end{tabular}

At $\mathrm{m}$. VI-17, the process begins to reverse-another suggestion of retrograde symmetry. Measure VI-17 presents an ascending contour of seven notes. After a rest, $\mathrm{m}$. VI-18 presents a descending contour of seven notes, the retrograde or inversion of the contour of $\mathrm{m}$. VI-17. As the last five notes of $\mathrm{m}$. VI-17 and the first five of m. VI-18 are contiguous members of octatonic collections, they are also pitch- or pitch-class transformations of each other by transposed retrograde or inversion. After these two one-measure passages, which together have a range of 13 semitones, comes a two-measure passage beginning at m. VI-19-the end of which is shaped like a retrograde-inverted checkmark-with a range of 16 semitones.

At $\mathrm{m}$. VI-21 begins a three-measure passage (followed by one measure rest) with the general contour of an inverted checkmark, which is closely modeled after mm. VI-5-8. This passage, like the first of chorus VI, ascends to Ab6 and descends to $\mathrm{A} 4$, producing a range of 23 semitones. With that process having been completed, the rest of the chorus winds down to end the piano solo portion of the performance. The small up4RS contour standing alone in $\mathrm{m}$. VI-25 is, perhaps surprisingly, one of the figures adopted by other pianists. Two more passages end the chorus. The first, beginning at $\mathrm{m}$. VI-26, generally descends, ending as in $\mathrm{m}$. I-15. In the next, beginning at beat four of $\mathrm{m}$. VI-29, the top voice of a polyphonic line presents the polyrhythm four against three, as there are four equally spaced upper-voice notes in the time of three half-measures (Example 22). Successive intervals between pitches in the descending line, $<F \#, F, E$, 
$\mathrm{D}, \mathrm{C}, \mathrm{B} b, \mathrm{~A}, \mathrm{G}>$, have durations (in eighth notes) of $3,3,3,3,2,3,3$, and 4 respectively. Despite the nearly equal durations, the passage is directional because of the stepwise descent of the upper voice and its counterpoint with an ascending lower voice, $\langle\mathrm{D}, \mathrm{D} \sharp, \mathrm{E}, \mathrm{F} \#, \mathrm{G}>$. Both lines close in on the goal, G4. Embedded in the passage, which is completed in the first measure of chorus VII, is a down5RS contour.

Example 22. Descending upper line and down5RS contour, mm. VI-29-VII-1.

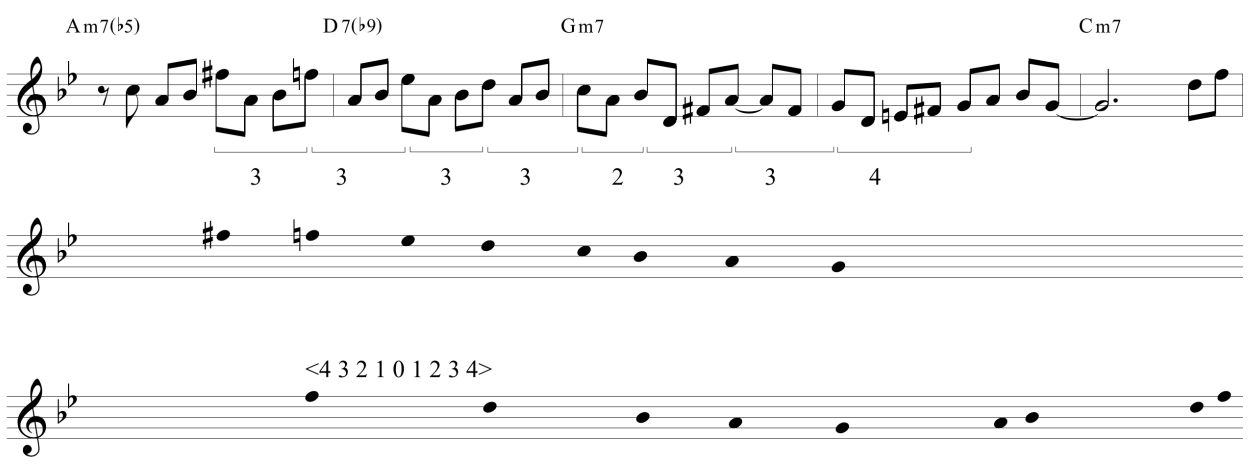

\section{CHORUS VII}

This chorus is devoted to the Evans trio version of "trading fours," a complex imitative interaction of varying durations among the three players. Here, the bass takes the lead. Evans responds in mm. VII-5-6 with an up5RS contour ending on the anticipation to beat four. This passage proceeds in parallel tenths between the two hands, recalling the parallel thirds of $\mathrm{mm}$. III-11-16. His response at VII-9-10 begins on the second half of the downbeat, ends on the fourth beat, and returns to the octave doublings associated with the bass solo of choruses II and III. In this passage, a reduction to arpeggiations of chord components in thirds yields interlocking contour $<135420>$, the inversion of which is $<420$ $135>$, in which invariant segments $\langle 135\rangle$ and $\langle 420\rangle$ appear in reverse order (Example 23). The next passage, $\mathrm{mm}$. VII-13-14, begins and ends in the same metric positions as the preceding passage and consists of a two-statement sequence on the interlocking contour $<02431$ >, the retrograde inversion of which holds segments $<024>$ and $<31>$ invariant in reverse order (Example 24). It also brings back the characteristic rhythmic pattern used in chorus VI. As in chorus III, the introduction of relatively dense vertical chords (mm. VII-17-20) and the return to parallel tenths (mm. VII-23) suggest a small form: this time, ABA'. Measures III-29 and VII-22 correspond exactly in that they each begin 
with a three-note chord, but VII-22 functions as a retransition to A'. The B section here (m. VII-17) introduces an octatonic subset, 5-32 [01469], in a gesture that is similar to the octatonic subsets of the B section to chorus III-2627. The descending line of $\mathrm{m}$. VII-22 acts as an anacrusis to the up5RS contour in tenths at mm. VII-23-24, which presents six notes of the octatonic scale, completing Evans's contribution to the chorus (Example 25).

Example 23. Interlocking contour, mm. VII-9-10.

$\mathrm{Cm} 7$

F 7

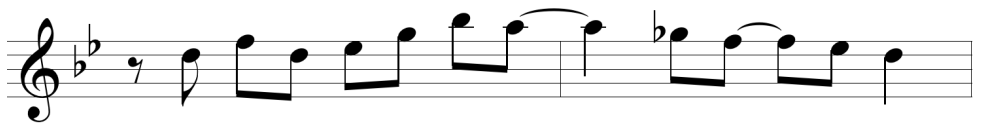

$<135420>$

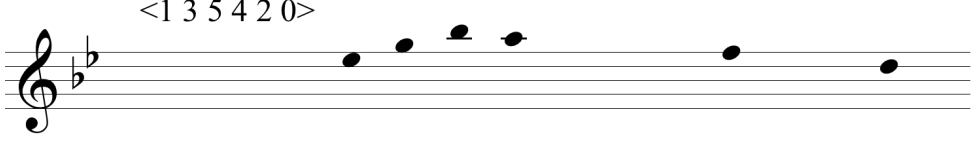

Example 24. Interlocking contours, mm. VII-13-14.

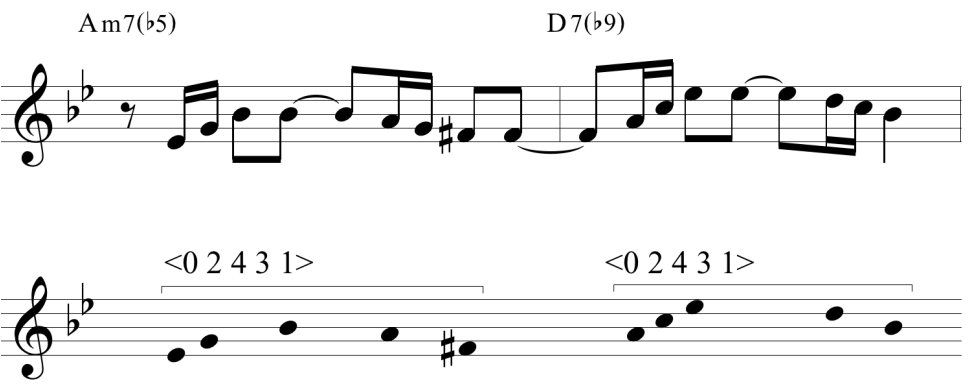

Example 25. Up5RS contour, mm. VII-23-24.

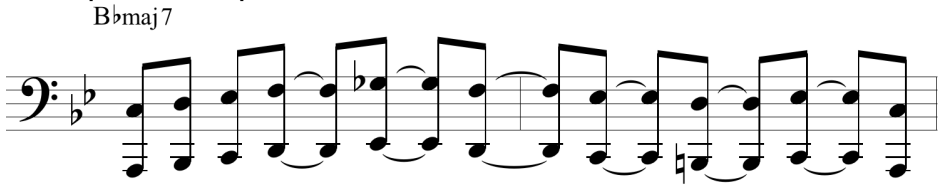

$<012343210>$

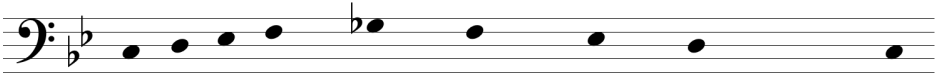




\section{CHORUS VIII}

As is usual, the last chorus paraphrases the original melody. Even so, ongoing processes dominate its treatment. As in the first chorus the upper voice line $<\mathrm{E} b$, $\mathrm{D}, \mathrm{C}, \mathrm{B} b>$ is maintained; however, the ascending pickups to these notes apply only to the first three. Again, each pickup is varied: the $\mathrm{E} b$ is approached by the three original pickups, the $\mathrm{D}$ by a stepwise line of six eighth notes, and the $\mathrm{C}$ by a mostly stepwise seven-note line of mixed rhythm. Also the third and fourth beats of pickup measures VIII-2 and 4 are harmonized in thirds, a procedure to be used to a great extent later in the chorus. In mm. VIII-5-8 Evans begins to vary the upper-voice line. The $\mathrm{C}$ is given two upper neighbors in a hemiola rhythm based on 6/4 against the underlying 4/4, and the $\mathrm{B} b$, which has no pickup, is buried in a descending blues-inflected line which ends with the Et that so often has ended phrases of the A section of the tune.

Measures VIII-9-15 present a passage of parallel thirds alternately ascending and descending over a gradually widening range: (1) C5 up to B5 back to C5: 11 semitones, (2) Bb4 up to Bb5: 12 semitones, (3) Bb5 down to A4: 13 semitones, (4) A4 up to Eb6: 18 semitones, and (5) Eb6 down to D4 at the end of the phrase in m. VIII-16: 25 semitones. In these sweeping gestures, which of course contain retrograde-symmetrical cores, it is the upper voices of the low points, located at or near the downbeats of the measures, that trace the descending line $<\mathrm{E} b, \mathrm{D}, \mathrm{C}, \mathrm{B} b>$ (however, the last note is displaced up an octave at VIII-15). In addition to the process of range expansion, repetition and compression contribute to the sense of forward motion in this passage. The first statement of ascentdescent (mm. VIII-9-10) has a temporal gap between its first and second elements and it is separated from its subsequent repetition by a quarter rest. The first repetition of this gesture (mm. VIII-11-12) has no gap and is joined directly to the next repetition (m. VIII-13), so that the repetitions are compressed. The descent of this second repetition is elaborated. Reduction reveals a descending line, <D6, C6, Bb5 A5, G5>, which occupies seven beats beginning at the downbeat of $\mathrm{m}$. VIII-14 (Example 26). Reduction of the short single line codetta immediately following the thirds ( $\mathrm{mm}$. VIII-15-16) reveals a repetition of the same line an octave lower compressed into four beats beginning at the fourth beat of m. VIII-15. Measures VIII-14-16 also contain compression of time values: triplet quarters, eighths, triplet eighths, and finally sixteenths. 
Example 26. Elaborated descents and hidden repetitions, mm. VIII-14-16.

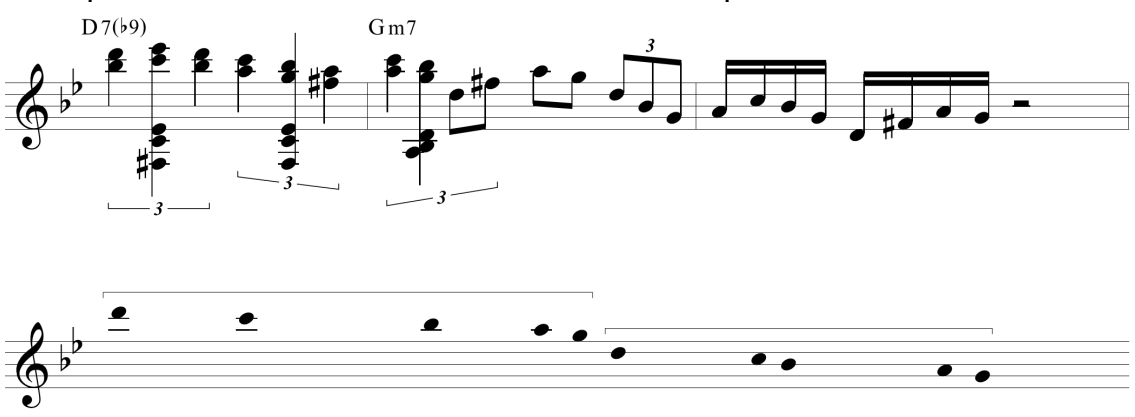

$\mathrm{A}$ and $\mathrm{B} b$, the structural pitch classes of the original melody at the beginning of the B section, occur on the downbeats of mm. VIII-18 and 19 respectively. The section begins with an ascending arpeggio very like the ones in the B section of chorus III. The next short passage in mm. VIII-18-20 partly balances this with its descending shape. It begins with the melodic adjacency $<\mathrm{G} 4, \mathrm{~A} 4>$, a compressed repetition of the first and last pitch classes of the ascending arpeggio that immediately precedes it. In addition, the descent of the opening up3RS contour, $\langle\mathrm{B} b, \mathrm{~A}, \mathrm{G}\rangle$, is repeated and compressed an octave lower at the end of the passage (Example 27).

Example 27. Up3RS contour and repetition of descent, mm. VIII-19-20.

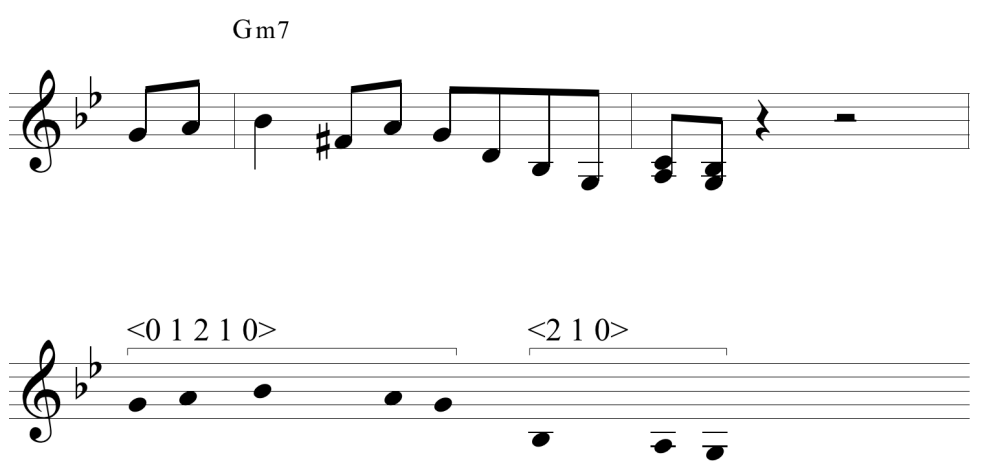

In mm. VIII-21-29, original melodic pitches $\mathrm{C}, \mathrm{F}$, and $\mathrm{D}$ are embedded in a sequential development of the ascending fourth motive. The pitch series, with notes of the original tune underlined, and ascending fourths in parentheses, follows: $<(\underline{\mathrm{C}} 5, \underline{\mathrm{F}} 5), \underline{\mathrm{C}} 5,(\underline{\mathrm{B} b 4}, \underline{\mathrm{E} b 5}),(\underline{\mathrm{A}} 4, \underline{\mathrm{D}} 5),(\underline{\mathrm{G}} 4, \underline{\mathrm{C}} 5)>\left(\right.$ Example 28). ${ }^{35}$ This

${ }^{35}$ Brackets in the score indicate the ascending fourths. 
pitch series is a compound melody harmonized by a series of sustained chords. The durations of these chords are gradually somewhat shortened; the series of durations in eighth notes is $\langle 9,8,8,8,8,6,8,6,1\rangle$ (see transcription). The upper voice of the compound melody, which continues in stepwise descent to a final goal of $\mathrm{B} b$ in $\mathrm{m}$. VIII-35, undergoes a greater degree of compression; its pitches and durations, in eighth notes, are: <F5 (24), Eb5 (14), D5 (14), C5 (13), B b4 (1), A4 (15), G4 (1), F4 (13), Eb (1), D4 (8), C4 (1)>. The final tonic note of the original melody, had it been played, would have occurred at m. VIII-31. At this point Evans's descending line has reached the pitch A4 and the harmony V7 of IV, which suggests that the rest is coda. The final tonic of this coda takes the form of an elaborately arpeggiated $\mathrm{G}$ minor seventh with ninth and eleventh. Interestingly, the bass chooses to end on what I have called the "odd" note, with which Evans ended so many of his phrases, E .

Example 28. Correspondence with original melody and upper-voice descent, mm. VIII$21 \mathrm{ff}$.
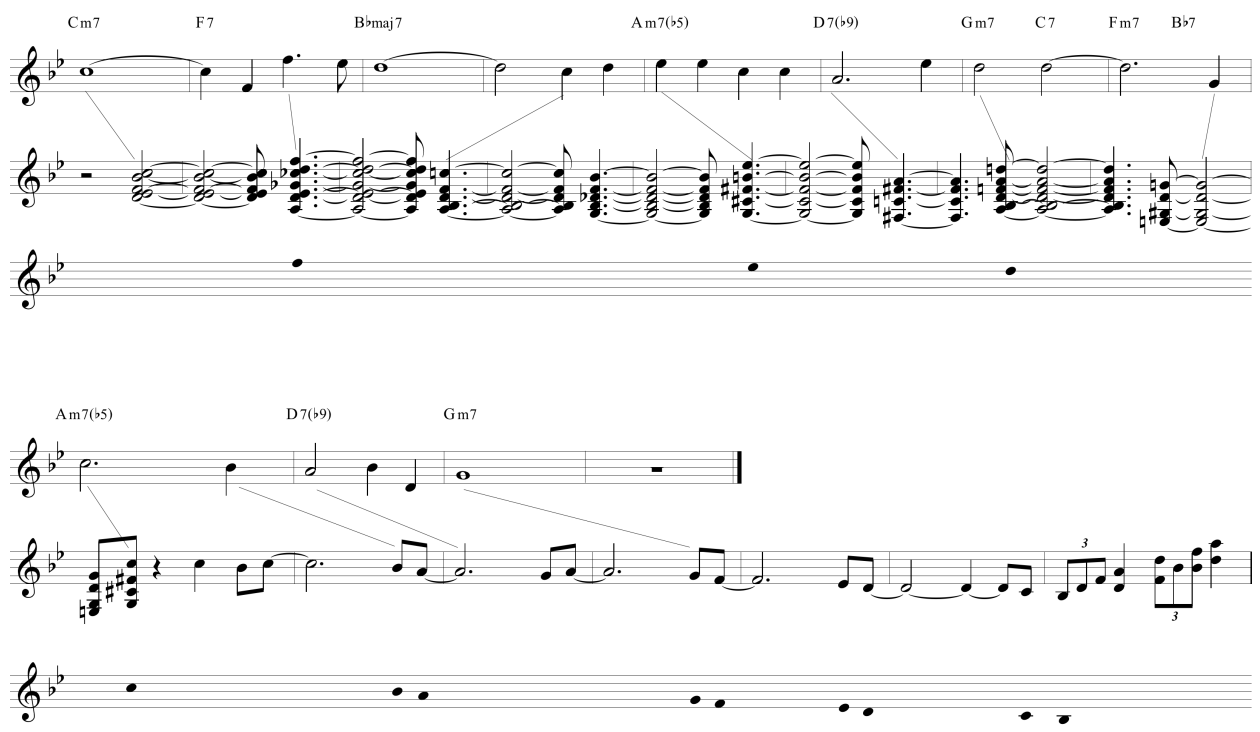

\section{THE PERFORMANCE AS A WHOLE}

An overview of the performance shows that retrograde symmetry is also suggested by its formal layout. It is framed by an introduction and a coda, the harmony of each of which approaches the final tonic through circle-of-fifths progressions. Choruses I and VIII each elaborate the original melody. Choruses II and III correspond with VII, as they take the focus off the piano, presenting the bass as the leading voice (with drums participating as well in VII), and 
having most of the piano lines doubled in octaves throughout. Chorus III particularly corresponds with VII in that, in each, a small form is presented (AA'BA" in III, ABA' in VII), the B section of which features octatonic chords. Also the parallel thirds in III-11-16 have a counterpart in the parallel tenths of VII-5-6. The central piano solo section (Choruses IV, V, and VI) does not appear to be symmetrically organized. Chorus IV introduces numerous liquidations. Chorus $\mathrm{V}$ develops the eighth note triplet motive while introducing the expansive motive (at V-9-11 and V-25-26) that reaches its peak at the beginning of Chorus VI. That chorus gradually reduces the scope and energy of the expansive motive while presenting melodic octatonic subsets that lead into Chorus VII. On the whole, the performance exhibits retrograde symmetry around the central piano solo, and in that aspect correlates with the emphasis on symmetry and invariance exhibited by the surface melodic features.

The methods of melodic construction discussed in this paper generally support the values desired in improvisation. An improviser who, as he or she plays, reveals to us conceptions which seem both unified and fresh, and yet which, in retrospect, seem inevitable, demonstrates the art of improvisation at its highest level. Contributing to unity in this performance are the symmetric aspects of the materials just discussed and the recurrence and development of motives. Contributing to freshness are (1) Evans's use of weakly bounded phrases that start and end at weak rhythmic moments, and which contradict the phrase boundaries of the original tune; (2) his seemingly conscious use of octatonic subsets both horizontally and vertically; and (3) his rhythmic complexities (i.e., the polyrhythms and displacements). Contributing to inevitability are the techniques by which a substantial segment of time is organized and given a sense of direction toward a goal. These include liquidation, the sentence, the imposed three-part forms, and the growth or decline of successive passages in terms of duration, range, or both. Perhaps these remarkable achievements help to explain why, in the view of many listeners, this performance is "preferred."

\section{BIBLIOGRAPHY}

Berliner, Paul F. Thinking in Jazz: The Infinite Art of Improvisation. University of Chicago Press, 1994.

Blancq, Charles. "Bill Evans: The First Trio.” Jazzforschung 21 (1989): 55-69.

Hentoff, Nat. "Introducing Bill Evans.” Jazz Review 2 (October, 1959): 26-28. 
Hinz, Bob. The Artistry of Bill Evans Volume 2. New York: Warner Bros. Publications Inc., 1995.

Jazz Piano: A Smithsonian Collection. [Liner notes] Smithsonian Collection of Recordings, 1989.

Larson, Steve. "Rhythmic Displacement in the Music of Bill Evans." In Structure and Meaning in Tonal Music: Festscrift in Honor of Carl Schachter, edited by L. Poundie Burstein and David Gagné, 103-122. Hillsdale, NY: Pendragon Press, 2006.

. Musical Forces: Motion, Metaphor, and Meaning in Music. Bloomington: Indiana University Press, 2012.

Lees, Gene. "Inside the New Bill Evans Trio." Downbeat 29 (November, 1962.): 24-26.

Martin, Henry. "In Memoriam Steven Strunk.” Jounal of Jazz Studies 11 no. 1 (2016): iii-v.

Morgenstern, Dan. "Classic Interview-Bill Evans: The Art of Playing." Downbeat 61 (December, 1994): 46-47. [Originally published October 22, 1965: 15-16.]

Morris, Robert. Composition with Pitch Classes: A Theory of Compositional Design. New Haven: Yale University Press, 1987.

Nelsen, Don. "Bill Evans: Intellect, Emotion, and Communication." Downbeat 27 (December, 1960.): 16-19.

Rahn, John. Basic Atonal Theory. New York: G. Schirmer, 1980.

Schoenberg, Arnold. Models for Beginners in Composition. New York: G. Schirmer, 1942.

. Fundamentals of Musical Composition, ed. Gerald Strang and Leonard Stein. New York: St. Martin's Press, 1967.

Waters, Keith. "Outside Forces: 'Autumn Leaves' in the 1960s," Current Musicology 71-73 (2001-2002): 276-302. 
Appendix A. Steven Strunk's transcription of Bill Evans's “Autumn Leaves” performance from Portrait in Jazz.
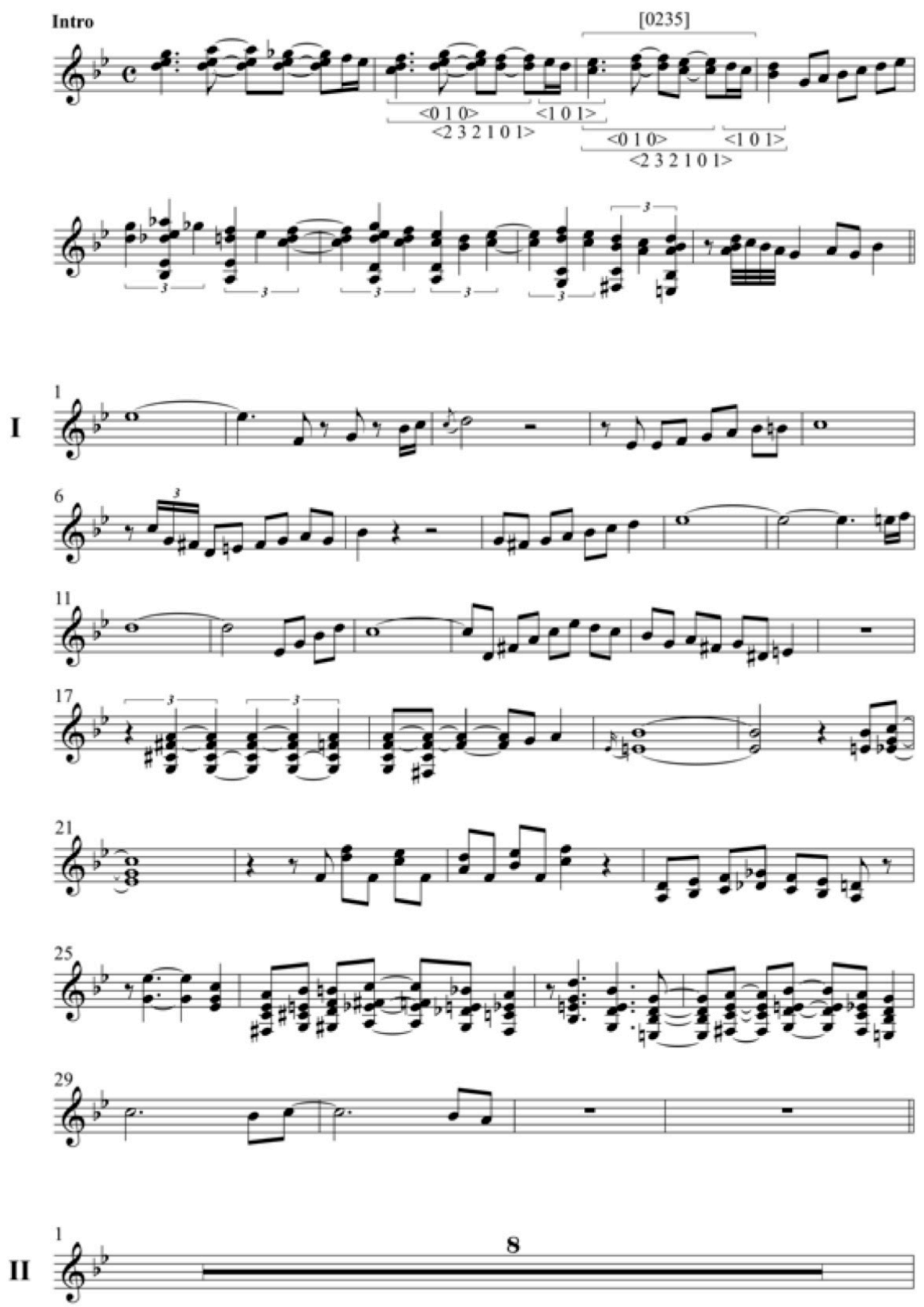

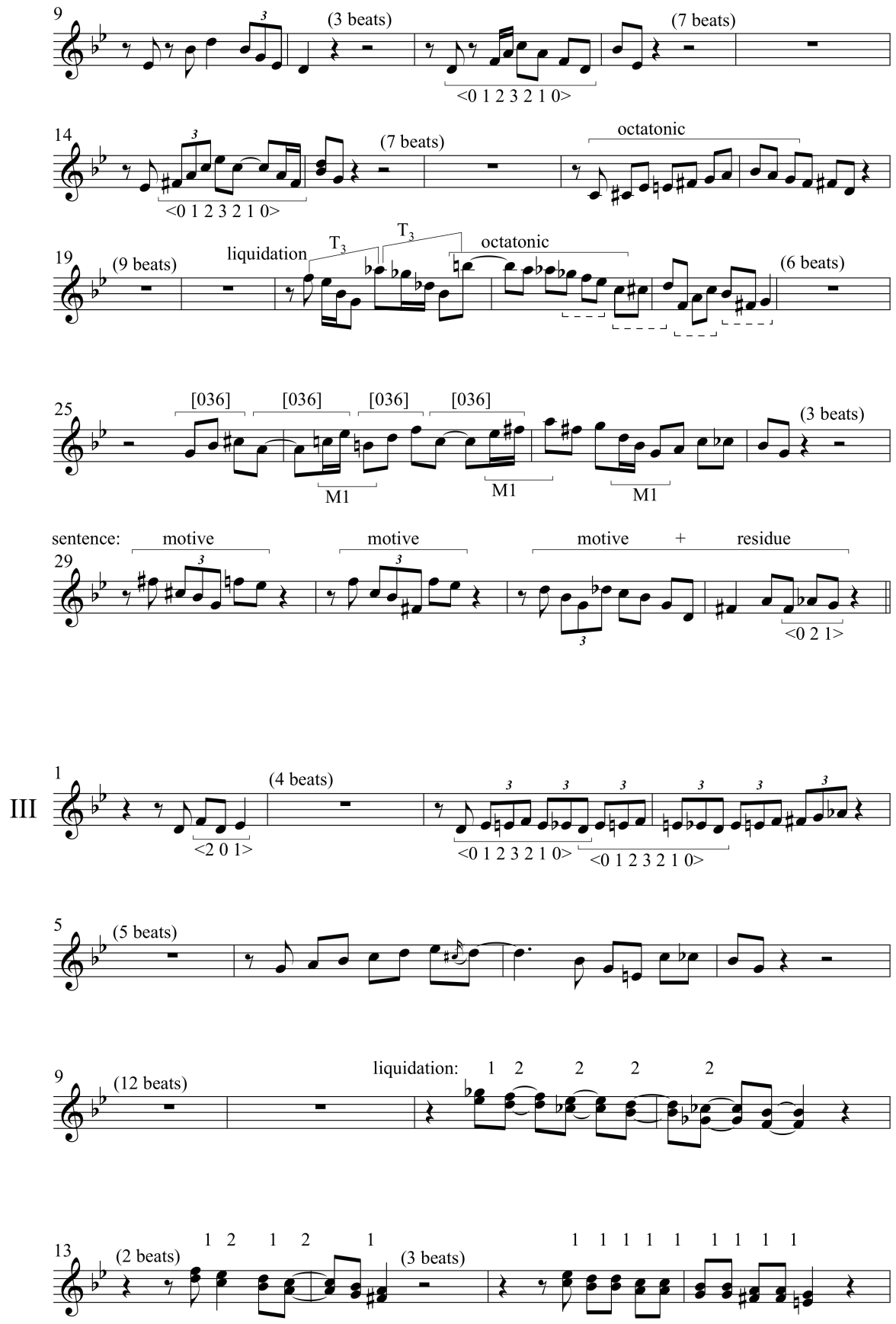

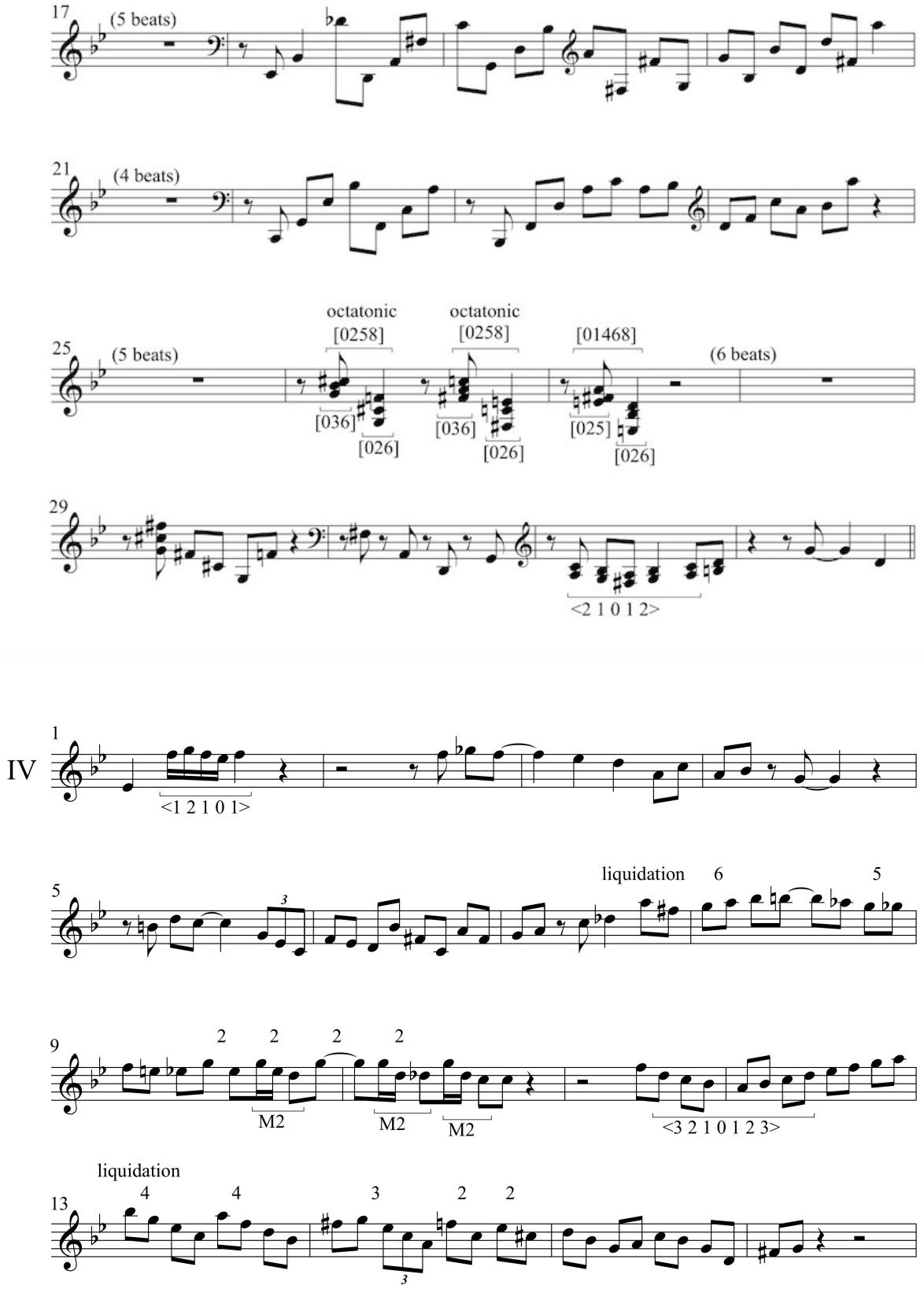

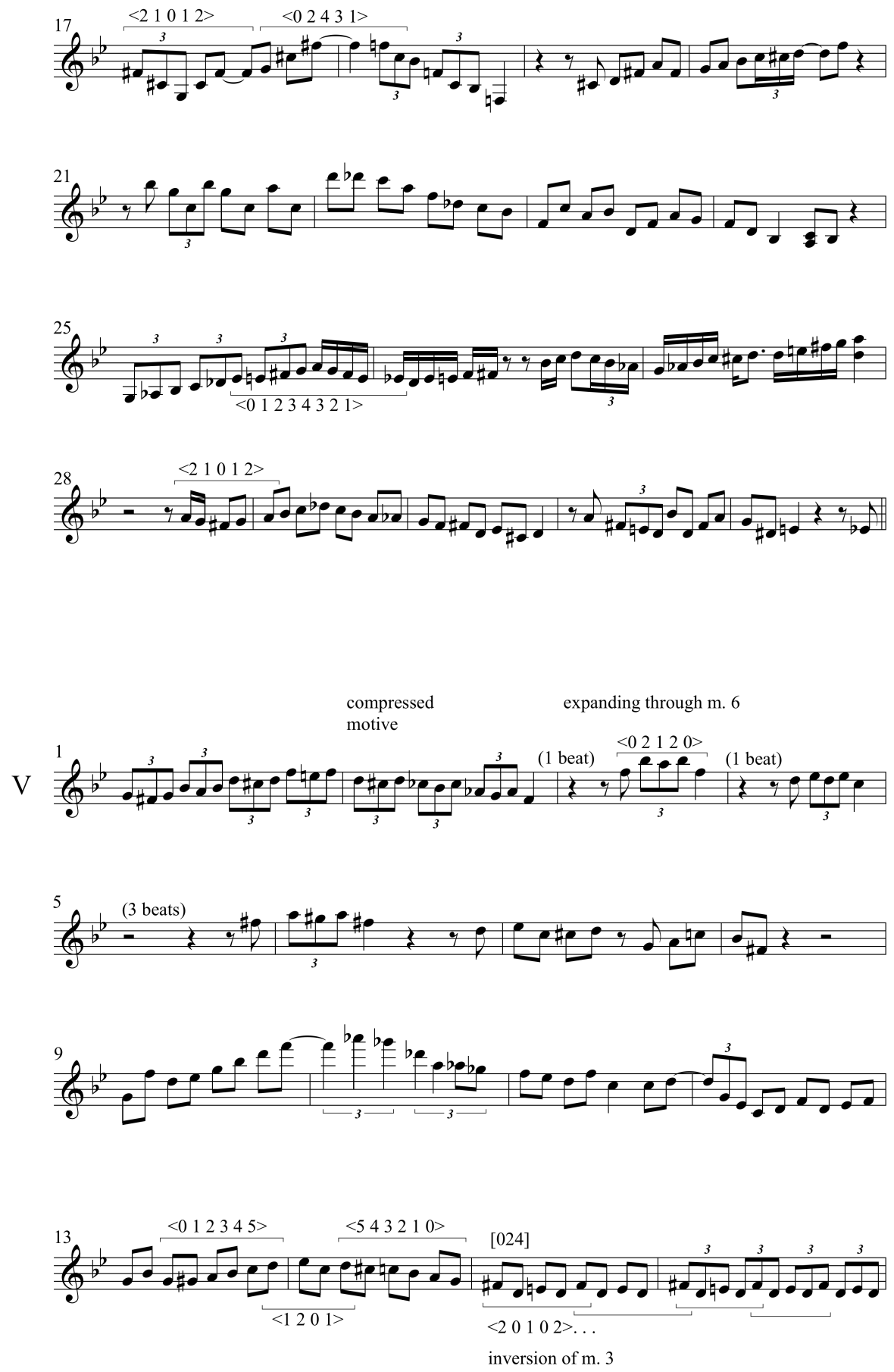

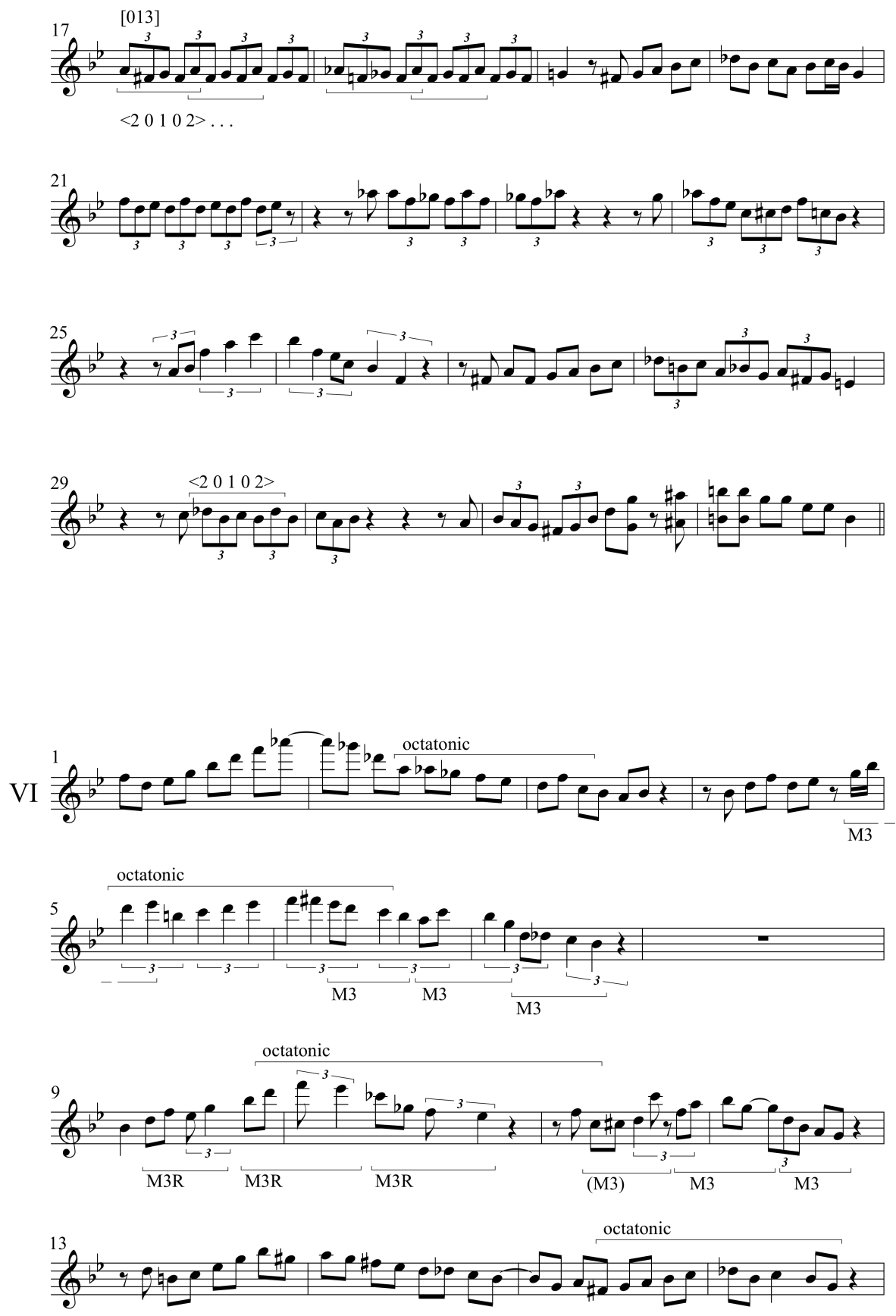

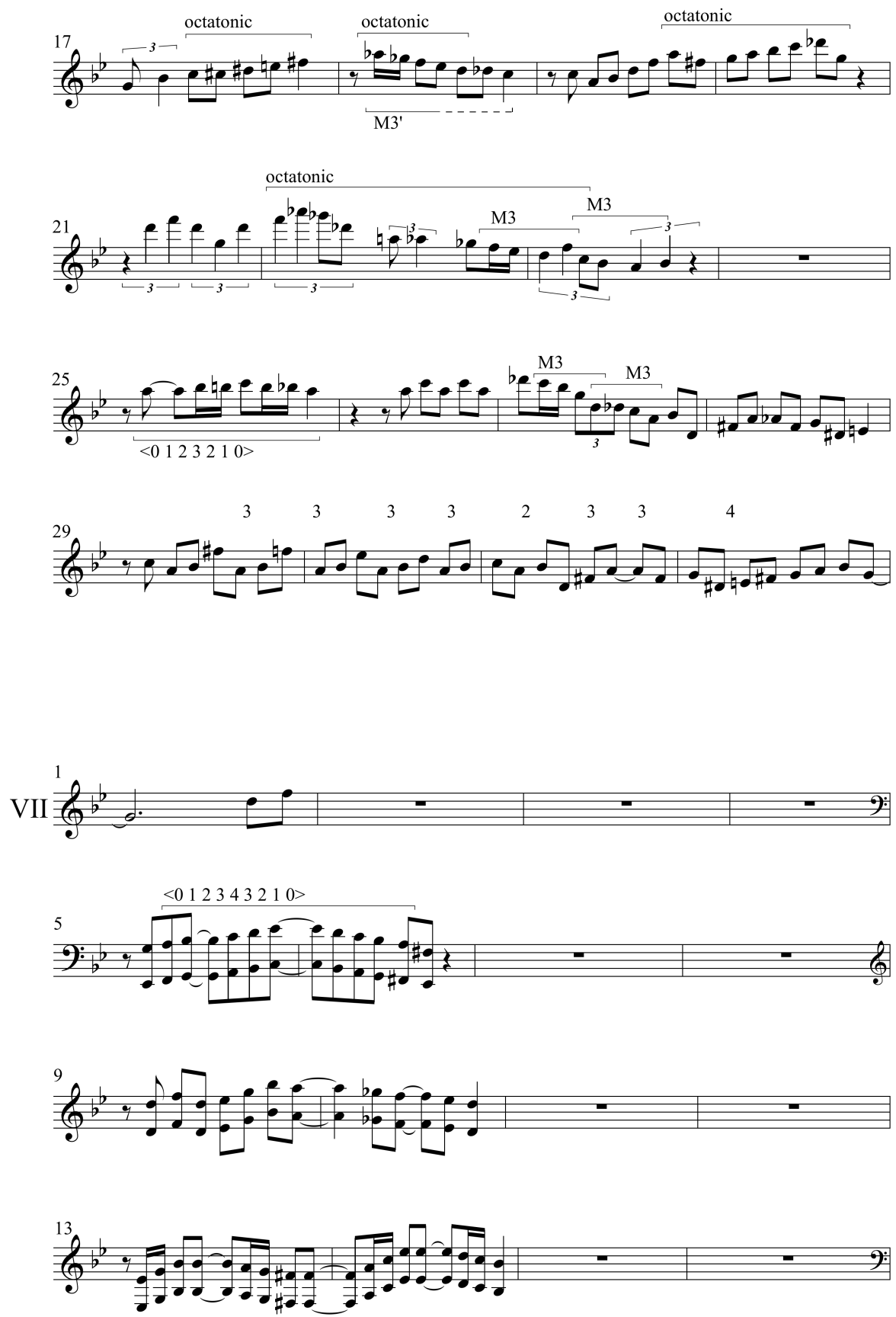

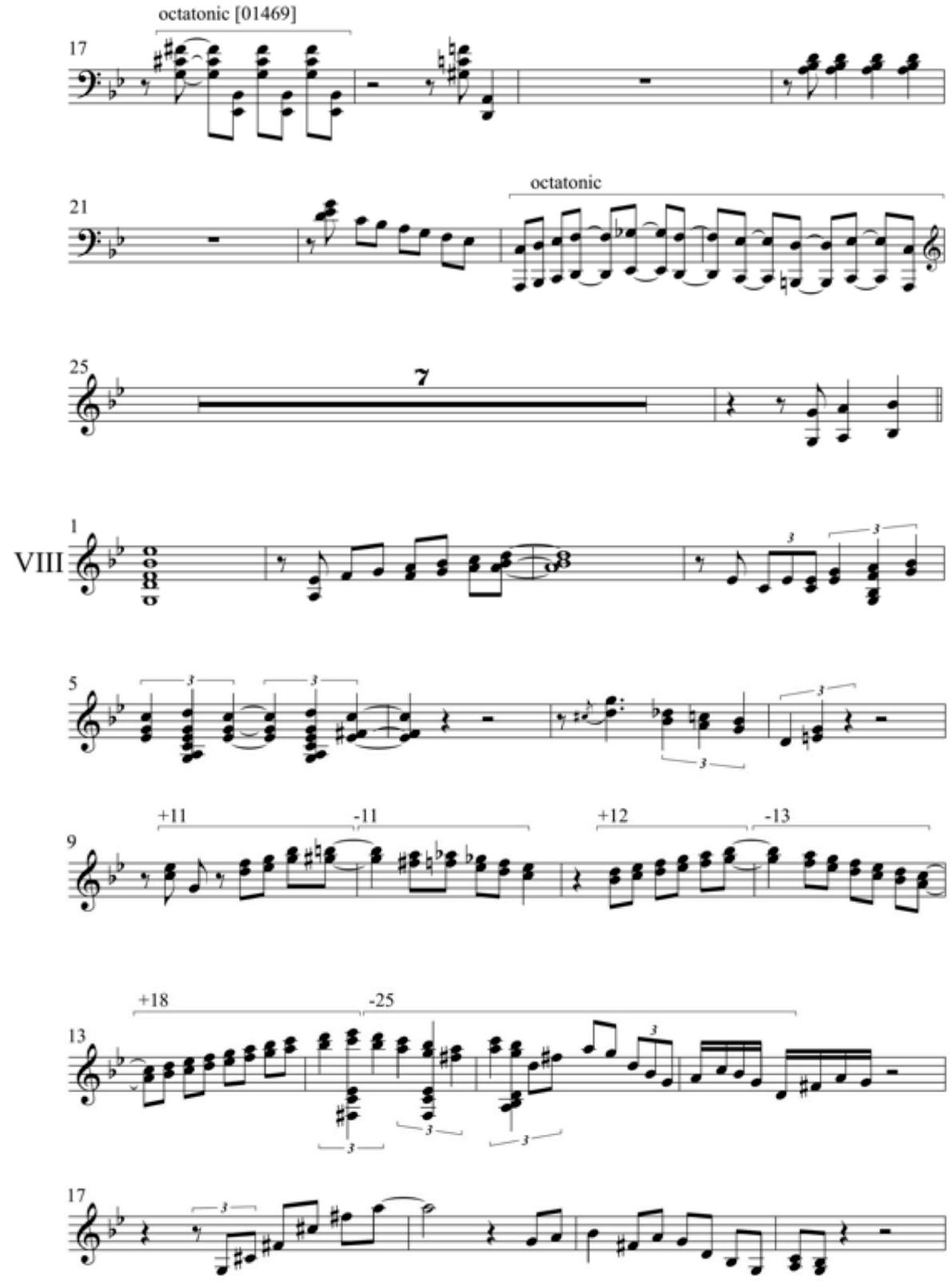

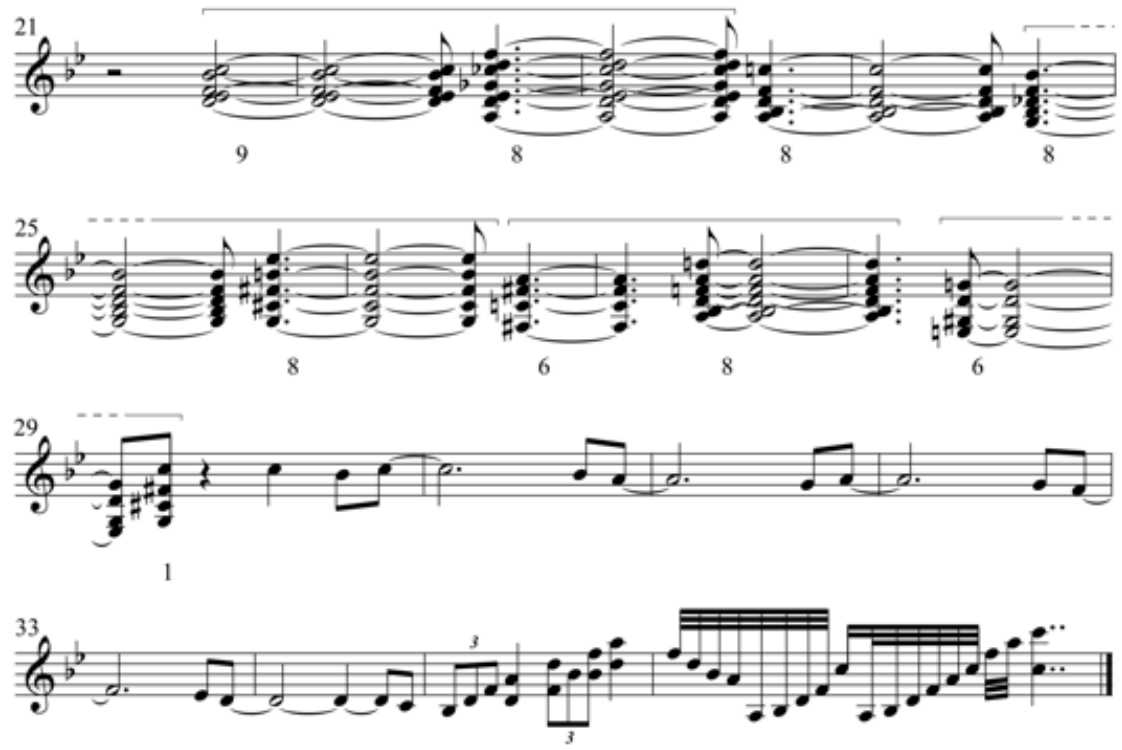

\section{ABOUT THE CONTRIBUTOR}

Steven Strunk was Professor of Music at the Benjamin T. Rome School of Music at the Catholic University of America until his death in 2012. He contributed seminal articles on jazz theory to the Journal of Jazz Studies, the "Harmony" entry in the New Grove Dictionary of Jazz, and articles on the music of Wayne Shorter and Chick Corea to the Journal of Music Theory. Strunk was also a practicing composer as well as a jazz pianist who performed extensively in the Washington D.C. area. 